\title{
Flow Visualization of Footballs to Analyze the Factors Affecting their Aerodynamic Performance Using CFD
}

\author{
Chandan Varma Tamada \\ Department of Mechanical Engineering \\ Andhra University College of Engineering (A) \\ Visakhapatnam, India
}

\author{
Sai Ganesh Sabbavarapu \\ Department of Mechanical Engineering \\ Andhra University College of Engineering (A) \\ Visakhapatnam, India
}

\begin{abstract}
The motion of a football in air is influenced by the combination of various aerodynamic effects caused by the parameters such as velocity, surface roughness, panel orientation and shape. This paper analyzes the individual and combined effects of these parameters on the flight characteristics of various footballs using CFD Analysis. Four balls, a smooth sphere, a 32-panel conventional football, 14-panel Teamgeist and 6-panel Brazuca ball are subjected to different velocities of air flow over them, both in the laminar and turbulent regime, different surface roughness values and the influence of these parameters on the aerodynamics of the balls is evaluated by the drag force, drag coefficient and hydrodynamic boundary layer separation angle. The effect of the seam length, number of panels and panel orientation are also compared. The results of these effects are discussed later in the paper and are used to explain the knuckling effects and unpredictable trajectory of the Jabulani ball.
\end{abstract}

Keywords:- Aerodynamic effects, Panel Orientation, CFD, Hydrodynamic Boundary Layer, Seam length, Knuckling effects.

\section{INTRODUCTION}

The design of a football involves consideration of various aerodynamic parameters to optimize its flight characteristics. The design of football has evolved from the standard 32-panel design made up of hexagonal and pentagonal shaped panels joined by external stitching to the 6 panel thermally bonded footballs with different panel shapes. The fascinating changes in football design drags the attention of researchers to study the influence of these design modifications on the aerodynamic performance. This begins with the work made by Achenbach for the study of flow over rough spheres using wind tunnel experiments ${ }^{[1]}$. Researchers worked on the Analysis of footballs using Wind tunnel experiments to examine the basic Aerodynamic behavior of Footballs ${ }^{[3,9]}$, effects of panel shape ${ }^{[8]}$ and surface characteristics ${ }^{[10]}$. The recent work focuses on comparing the aerodynamics of FIFA approved footballs ${ }^{[4-7,11,12]}$. Understanding the parameters that control the flight characteristics helps predict the behavior of football and to identify the reasons for deviation of football trajectory from the anticipated path. It also helps in understanding the improvement in performance of modern footballs compared to traditional 32-panel football. This study focuses on using numerical simulation techniques to analyze the flow of air around a football and the factors influencing this flow.

The objective of this study is to determine the influence of design parameters of football on its flight characteristics. Different combinations of these parameters are considered and the flow around the ball is simulated using Ansys fluent. Variation of Drag, Lift and HBL separation angle with these parameters are presented in graphs. The values of $\mathrm{C}_{\mathrm{d}}$ and angle of boundary layer separation of traditional football and modern footballs are compared with those values of an ideal spherical ball to analyze the effect of these design parameters on flight characteristics of football.

\section{BACKGROUND}

The flow around a body is characterized by free stream velocity and Reynolds number. Free stream velocity represents the bulk velocity of the fluid medium flowing over the object. In numerical simulation, the football is assumed to be stationary whereas the surrounding air is simulated as flowing over the football and corresponding results are extracted.

\section{A. Reynolds Number}

Reynolds number determines the nature of flow around the object. Re is a dimensionless number defined as ratio of inertia force to the viscous force. Reynolds number $(\mathrm{Re})$ measures the domination of inertia forces over viscous force.

$$
R e=\frac{\rho V D}{\mu}
$$

Reynolds number for this study on football depends only on the flow velocity of air as the other parameter such as density and viscosity of air are assumed to be constant and the diameter of football is taken as $220 \mathrm{~mm}$.

Critical Reynolds number is the value of Re at which the flow in HBL changes from laminar to Turbulent which is characterized by minimum value of $C_{d}$. Critical $R e$ lies at the point where the transition from laminar to turbulent flow gets completed. Critical $\mathrm{Re}$ is characterized by Maximum value of HBL separation angle which will be discussed later. 


\section{B. Hydrodynamic Boundary Layer}

When a real fluid flows over a surface, a thin region is formed on the surface wherein the effects of fluid viscosity are concentrated. This region in which velocity gradient is present is called HBL, which forms due to the no slip boundary condition at solid surface caused by fluid viscosity. The behavior of HBL depends on the nature of flow, whether it is laminar or turbulent. Turbulent HBL has a fuller velocity profile and higher shear stress values than in laminar flow HBL, as the shear stress is caused due to fluid viscosity and turbulence.

\section{Surface Roughness}

All surfaces have some irregularities and roughness on them. The average height of surface irregularities on the outer surface of sphere is known by the parameter - surface roughness. The dimensionless quantity $\varepsilon / d$ is used to represent the surface roughness. Surface roughness does not affect the flow in laminar HBL but affects the flow in turbulent HBL. When the turbulent medium comes in contact with the surface, development of eddies takes place. If the average height of surface irregularities is less than the HBL thickness, the flow is not affected by surface roughness. However, the turbulent flow happens at higher Re at which the HBL thickness becomes very small so that the surface roughness value is usually greater than turbulent HBL thickness thereby influencing the flow. For this study, the roughness values of $0.11,0.55,2.75 \mathrm{~mm}$ are considered.

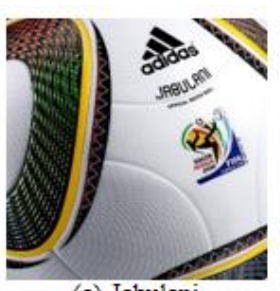

(a) Jabulani

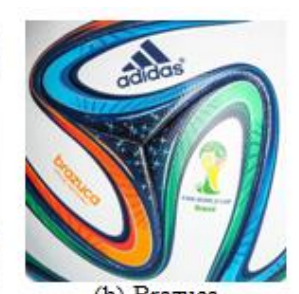

(b) Brazuca

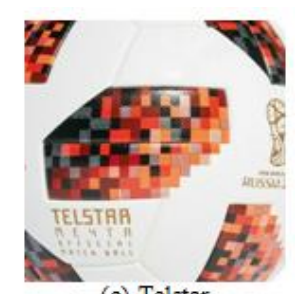

(c) Telstar
Fig 1:- Roughness patterns on FIFA footballs

\section{Drag Force}

A football moving in air is considered as a body submerged in air experiencing a free stream of air flowing over the it. Every elemental surface area on the ball experience a pair of forces caused by virtue of pressure and wall shear stress. The resultant force has two components. The force component against the direction of free stream is known as Drag force and the other component of force perpendicular to direction of free stream is known as lift force. Drag force opposes the motion of football in air. The components of drag force are pressure drag and friction drag.

$$
\begin{aligned}
F_{d} & =\frac{1}{2} C_{d} \rho A V^{2} \\
F_{l} & =\frac{1}{2} C_{l} \rho A V^{2}
\end{aligned}
$$

The value of projected area is taken as unity in Ansys fluent default settings. The actual projected area of Football of diameter $0.22 \mathrm{~m}$ is $0.038 \mathrm{~m}^{2}$. The $\mathrm{C}_{\mathrm{d}}$ values in this paper are calculated using the actual projected area of $0.038 \mathrm{~m}^{2}$.

\section{E. Hydrodynamic Boundary Layer Seperation Angle}

The shape of the object determines the flow of the streamlines on the surface of the object. When air is flowing over a sphere, the kinetic energy of air particles is completely converted into pressure energy at stagnation point. The streamlines flow over the surface up to the top of the sphere with increasing velocity and pressure is minimum towards the top most point of sphere. The streamlines then diverge and move towards the rear side. The presence of positive pressure gradient which is also called as adverse pressure gradient causes the HBL to separate from the surface of sphere and creates a lowpressure region at rear side of sphere known as wake region, which is responsible for pressure drag component experienced by the sphere. The angle between the stagnation point and the point at which HBL separates from the sphere is measured from the center of sphere. This angle is known as Boundary layer Separation angle. The size of wake region depends on the HBL separation angle. Delay in HBL separation causes higher separation angle, creating narrow wake region and reduces the pressure drag.

\section{F. Knuckling Effects in Football}

In football, when a player strikes the ball in a way as to give it very little spin, the ball will flutter unpredictably from side to side. This unpredictable phenomenon is called as Knuckling effect. The velocity of football reduces after the player strikes the ball because of the drag force experienced by the football in its flight. When the velocity of football approaches the critical velocity at which the wake behind the sphere and the drag force acting on the ball sharply decreases, the HBL remains laminar on one side and turbulent on other side of the football. This creates an asymmetry in the wake that creates a sideways force resulting in the zigzag motion making the trajectory of football unpredictable. The smoother the football with fewer seams on the surface, the higher the value of critical $\mathrm{Re}$ resulting in significant knuckling effects. If the Aerodynamic performance of football varies with panel orientation, the Knuckling effects are increased.

\begin{tabular}{|c|c|}
\hline & Nomenclature \\
\hline $\mathrm{F}_{\mathrm{d}}$ & Drag Force \\
$\mathrm{F}_{1}$ & Lift Force \\
$\mathrm{C}_{\mathrm{d}}$ & Coefficient of Drag \\
$\mathrm{C}_{\mathrm{l}}$ & Coefficient of Lift \\
$\mathrm{Re}$ & Reynolds Number \\
$\mathrm{HBL}$ & Hydrodynamic Boundary Layer \\
$\theta$ & Hydrodynamic Boundary Layer \\
$\mathrm{V}$ & Separation Angle \\
$\rho$ & Velocity of Air \\
$\mu$ & Density of Air \\
$\mathrm{A}$ & Viscosity of Air \\
$\varphi$ & Projected Area \\
\hline
\end{tabular}




\section{METHODS}

\section{A. Design}

The Design of football changes in number, shape, surface roughness of the panels. The conventional football has 32 panels (20 hexagonal and 12 pentagonal panels). These panels are made up of synthetic leather and are externally stitched. The manufacture of externally stitched synthetic balls is very laborious. Thermally bonded footballs are different from the stitched balls in the way the panels are attached together. Panel design has changed significantly with the advent of thermal bonding. Reducing the number of panels with thermal bonding makes the football shape closer to sphere. The first major shift in the design of the ball came about in 2006 world cup in Germany, when Adidas introduced the Teamgeist. This ball had fourteen panels rather than the traditional 32 panels. In 2010 world cup, 8-panel ball named Jabulani was introduced in South Africa. Jabulani was one of the most controversial ball designs in world cup history ${ }^{[14]}$. The Adidas Brazuca was introduced as the official football ball of the 2014 FIFA World Cup held in Brazil. The ball was made of thermally bonded six polyurethane panels. The reduction in the number of panels improves the consistency in the ball. The Brazuca ball has been introduced to avoid aerodynamic problems with the Jabulani ball. The diameter of football is $220 \mathrm{~mm}$ and the seam length of different footballs are $384 \mathrm{~cm}$ for conventional 32-panel ball, $332 \mathrm{~cm}$ for Teamgeist, $347 \mathrm{~cm}$ for Brazuca ${ }^{[8]}$.

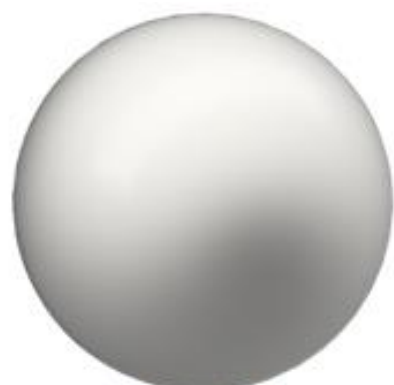

(a) Smooth Sphere

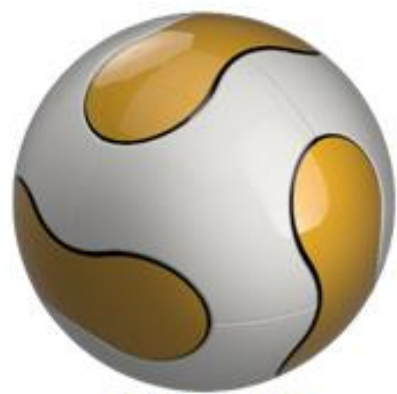

(c) Teamgeist

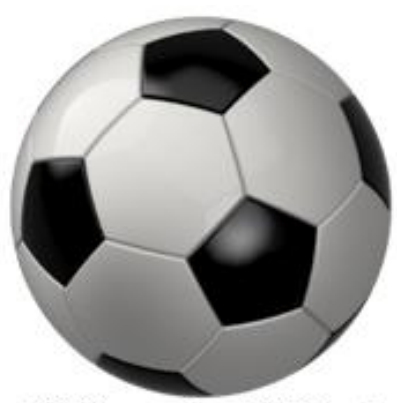

(b) Conventional 32-Panel Ball

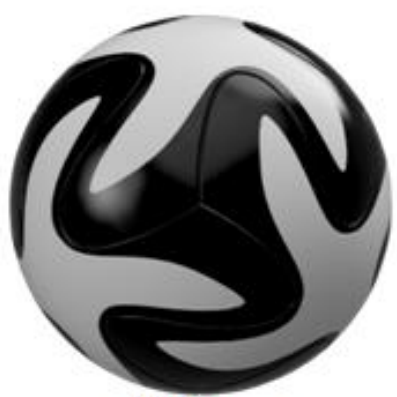

(d) Brazuca
Fig 2:- 3D models of Footballs designed and rendered in Autodesk Fusion 360

\section{B. Mesh Generation}

After modelling the footballs in Autodesk Fusion 360, the 3D model of football is imported to Ansys Workbench Version $2020 \mathrm{R} 1$. The fluid domain around the balls is modelled as enclosures and discretized in Ansys with tetrahedral elements. The mesh generated has 593504 elements with 111056 nodes for sphere enclosure, 362148 elements with 97382 nodes for 32-panel ball enclosure, 366299 elements with 98807 nodes for enclosure of Brazuca and 304097 elements with 81275 nodes for Teamgeist enclosure.

\section{Ansys Setup}

After Meshing, the solver model is to be selected based on the nature of the flow region. For laminar and transition flow region, Transition k-kl--omega and Transition SST are used whereas for turbulent flow region, K-epsilon Standard and Realizable wall function settings were used. Transition SST is preferred over Transition k-klomega as the sand-grain roughness is also included. The selection of suitable model is affecting the accuracy of CFD results when compared to the experimental data.

\begin{tabular}{|c|c|}
\hline \multicolumn{2}{|c|}{ Fluent Parameters } \\
\hline Fluid & Air, incompressible \\
\hline State & Transient \\
\hline Density & $1.225 \mathrm{~kg} / \mathrm{m}^{3}$ \\
\hline Temperature & $288.16 \mathrm{~K}$ \\
\hline Ratio of Specific heats & 1.4 \\
\hline Dynamic Viscosity & $1.789 \times 10^{-5}$ \\
\hline Turbulence Intensity & $101325 \mathrm{~Pa}$ \\
\hline Atmospheric Pressure & Pressure (Second Order) \\
& Momentum (Second Order \\
Discretization Scheme & Upwind) \\
\hline CFD Algorithm & Simple \\
\hline
\end{tabular}
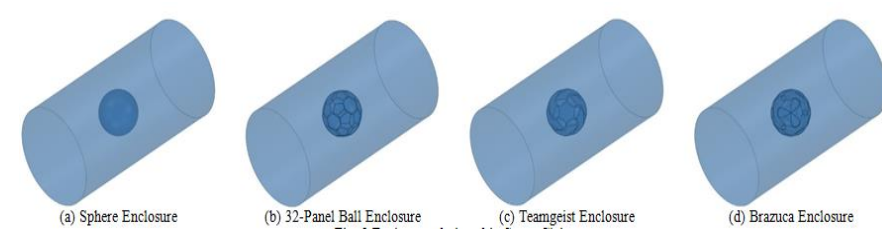

Fig 3:- Enclosures designed in Space Claim
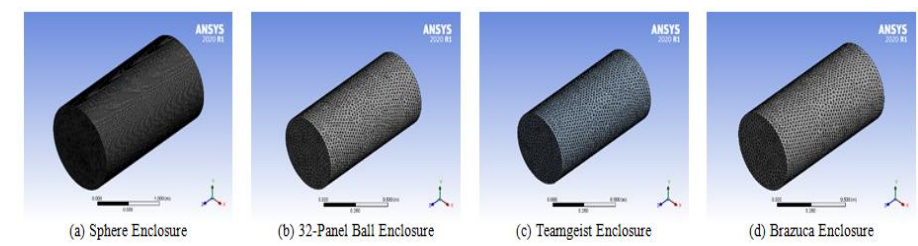

Fig 4:- Meshes generated in Ansys Fluent 


\section{RESULTS AND DISCUSSION}

\section{A. Influence of Surface Roughness on Sphere}

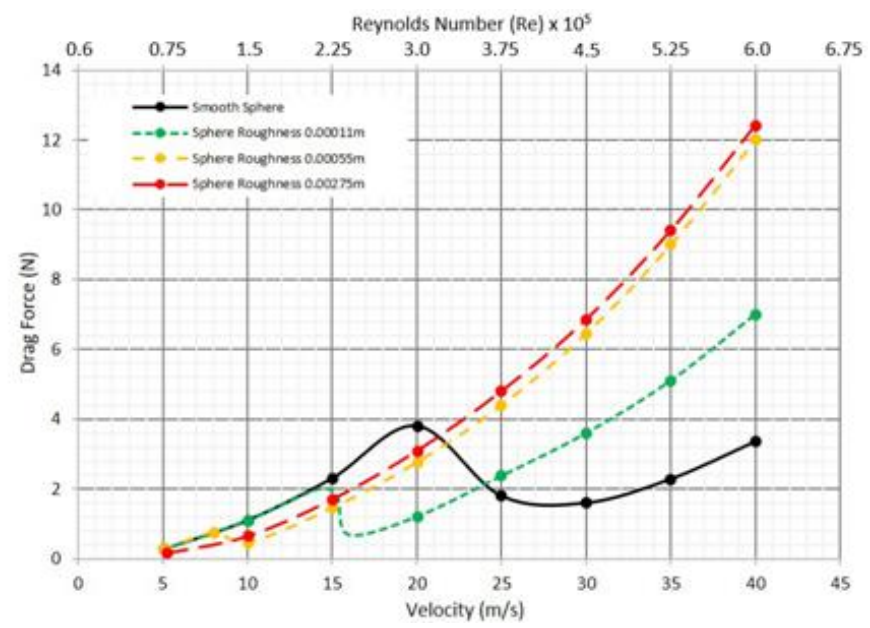

Fig 5:- Drag Force versus Velocity of Sphere with different surface roughness

For a smooth sphere, the flow in Hydrodynamic Boundary Layer remains Laminar up to a velocity of 20 $\mathrm{m} / \mathrm{s}$. The drag force increases as the velocity increases up to $20 \mathrm{~m} / \mathrm{s}$. There is a sudden decrease in drag force after 20 $\mathrm{m} / \mathrm{s}$ even though the velocity is increasing as the flow lies in Transition zone. The flow becomes Turbulent after 27 $\mathrm{m} / \mathrm{s}$ and drag force starts increasing with the velocity. For smooth sphere, $C_{d}$ lies in the range of 0.46 to 0.48 in laminar HBL. As the flow gets turbulent, $\mathrm{C}_{\mathrm{d}}$ falls to 0.08 at critical Re of $4.2 \times 10^{5}$. The HBL separation angle increases from $82^{\circ}$ in Laminar flow to $120^{\circ}$ in Turbulent flow. Laminar HBL cannot resist adverse pressure gradient and separates quickly from the surface whereas Turbulent HBL attaches to the surface as the fuller velocity profile increases wall shear stress and the lateral momentum exchange energies the HBL. Increase in HBL separation angle reduces the pressure drag because of smaller wake region that allows larger static pressure at rear side of sphere reducing pressure drag and therefore the value of $C_{d}$ decreases. Adding roughness to sphere results in variation of aerodynamic performance. Increasing surface roughness causes the flow to become turbulent quickly.

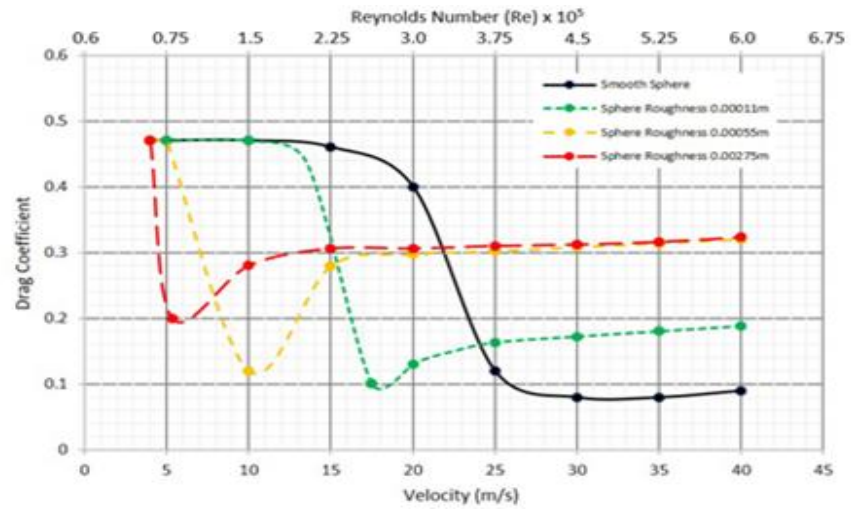

Fig 6:- Drag Coefficient versus Velocity of Sphere with different surface roughness
The surface irregularities interact with the HBL and change the flow to become turbulent even at lower $\mathrm{Re}$ values. From Fig. 6 It can be deduced that the critical Re decreases with increase in surface roughness. The drag force in turbulent region increases significantly with increase in Roughness $\left(\mathrm{R}_{1}, \mathrm{R}_{2}\right)$ and this variation in drag force is significantly high up to certain roughness value. Further increase in surface roughness of magnitude far greater than the laminar HBL thickness has lesser influence on drag force. At velocity of $30 \mathrm{~m} / \mathrm{s}$, smooth sphere has drag force of $1.6 \mathrm{~N}$. At $0.11 \mathrm{~mm}$ roughness $\left(\mathrm{R}_{1}\right)$, this force changes to $2.79 \mathrm{~N}$ (74.3\% increase in drag force). At $0.55 \mathrm{~mm}$ Roughness $\left(\mathrm{R}_{2}\right)$ which is 4 times greater than $\mathrm{R}_{1}$, the drag force increases to $4.77 \mathrm{~N}(70.96 \%$ increase in Drag force for $R_{2}$ compared to $\left.R_{1}\right)$. At $2.75 \mathrm{~mm}$ roughness $\left(R_{3}\right)$ which is 4 times greater than $R_{2}$, drag force at $30 \mathrm{~m} / \mathrm{s}$ is $5.10 \mathrm{~N}\left(6.91 \%\right.$ increase in drag force from $R_{2}$ to $\left.R_{3}\right)$. From the $F_{d}$ graph, there is no significant variation in drag force for roughness above $0.55 \mathrm{~mm}$. Drag force graph for $\mathrm{R}_{2}$ and $\mathrm{R}_{3}$ remains very close to each other. With increase in surface roughness, the $C_{d}$ value in turbulent region first increases and then reaches a maximum value of 0.32 at 40 $\mathrm{m} / \mathrm{s}$. Increasing roughness results in decrease in $C_{d}$ rapidly in sub-critical region, reaches minimum $C_{d}$ at critical $R e$ followed by increase in $\mathrm{C}_{\mathrm{d}}$ in trans critical region and remains constant in supercritical region.

\begin{tabular}{|c|c|c|}
\hline & $\begin{array}{c}\text { Critical } \\
\text { Reynolds } \\
\text { Number, } \mathbf{R}_{\mathbf{e}}\end{array}$ & $\begin{array}{c}\text { Critical } \\
\text { Velocity (m/s) }\end{array}$ \\
\hline Smooth Sphere & $4.2 \times 10^{5}$ & 28 \\
\hline $\begin{array}{c}\text { Sphere Roughness } \\
0.11 \mathrm{~mm}\end{array}$ & $2.4 \times 10^{5}$ & 16 \\
\hline $\begin{array}{c}\text { Sphere Roughness } \\
0.55 \mathrm{~mm}\end{array}$ & $1.57 \times 10^{5}$ & 10.5 \\
\hline $\begin{array}{c}\text { Sphere Roughness } \\
2.75 \mathrm{~mm}\end{array}$ & $0.87 \times 10^{5}$ & 5.8 \\
\hline
\end{tabular}

Table 1:- Variation of Critical Re of Sphere with its Roughness

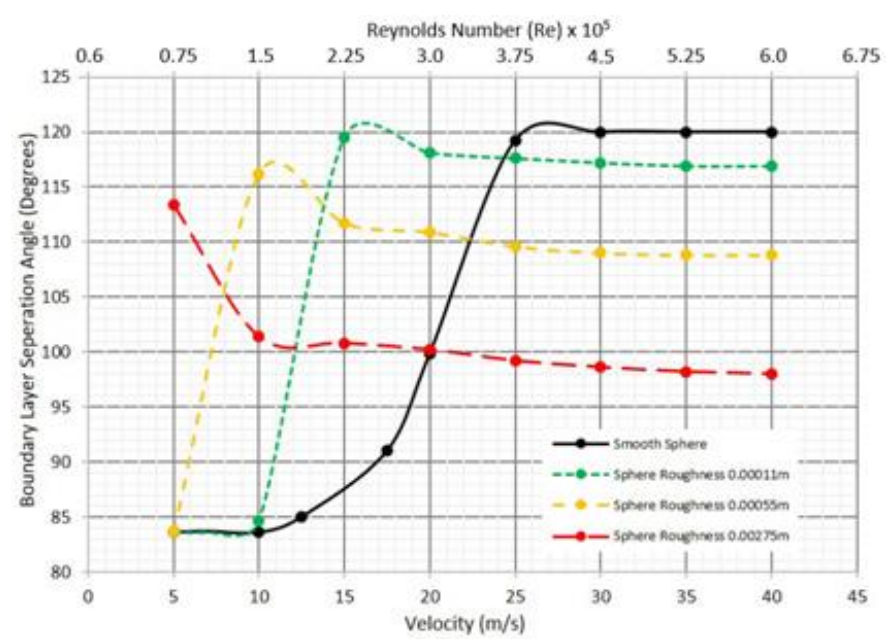

Fig 7:- HBL Separation Angle versus Velocity of Sphere with different surface roughness 
Fig. 7 shows the variation of HBL separation angle with respect to flow velocity at different surface roughness. Effect of surface roughness on separation angle depends on the nature of HBL. Surface roughness does not affect the Laminar flow as the viscous forces in laminar flow dampens the disturbances created by surface irregularities. If the average height of surface irregularities lies above the viscous sublayer, the surface roughness disturbs the turbulent flow. Minimum value of $\theta$ occurs in laminar HBL and $\theta$ increases in transition region and reaches maximum value at critical Re.

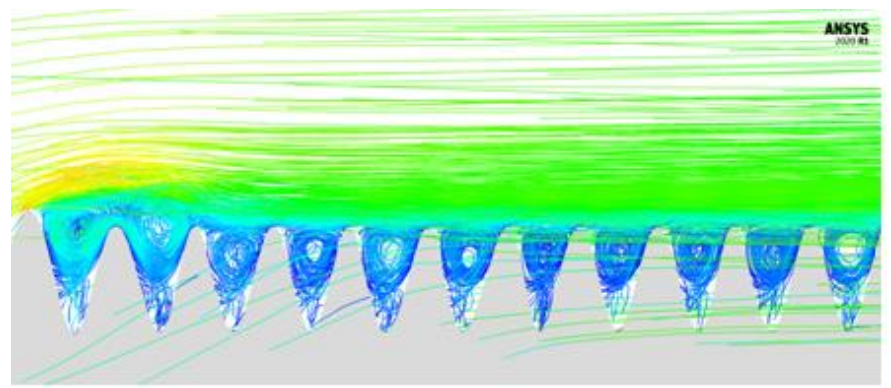

Fig 8:- Formation of Eddies due to surface irregularities in turbulent flow

Fig. 8 shows the streamlines in a turbulent flow over a surface with $2.75 \mathrm{~mm}$ roughness at $40 \mathrm{~m} / \mathrm{s}$. The interaction between surface irregularities with the turbulent flow creates eddies in the valleys of surface roughness. The formation of these eddies in between the surface irregularities results in loss of energy of HBL. Also, at higher Re (greater than Critical Re) for Rough sphere, the Inertia forces dominate the viscous force in such a way that the inertia of fluid particles and energy loss due to formation of eddies causes the HBL to separate quickly despite of surface irregularities holding the HBL. This can be observed in trans critical flow region as the value of $\theta$ reduces gradually with increasing $\mathrm{Re}$ because of the increasing inertia forces advances the HBL separation and $\theta$ remains constant in supercritical region as the inertia forces are of high magnitude so that streamlines cannot change their path to stick to the surface. However, in smooth sphere, there is no energy loss in HBL and effect of increasing Inertia forces can be observed at very high $\mathrm{Re}$ of order $10^{6[1]}$.

With the increase in surface roughness, the size of eddies increases, energy lost by HBL also increases, therefore the $\theta$ decreases. For $\mathrm{R}_{3}$ of $2.75 \mathrm{~mm}$ roughness, the entire velocity range of 5 to $40 \mathrm{~m} / \mathrm{s}$ lies in turbulent region so the $\theta$ decreases from $113.4^{\circ}$ to $100.2^{\circ}$ rapidly and then decreases to $98^{\circ}$ gradually.

In supercritical flow region, $C_{d}$ is independent of $\mathrm{Re}$ and at given velocity in supercritical region, increasing Roughness beyond a certain amount does not affect $\mathrm{C}_{\mathrm{d}}$. At $40 \mathrm{~m} / \mathrm{s}$, Sphere with Roughness $R_{2}$ of $0.55 \mathrm{~mm}$ has $\mathrm{C}_{\mathrm{d}}$ of 0.323 and $F_{d}$ of $8.79 \mathrm{~N}$ whereas for sphere with Roughness $R_{3}$ of $2.75 \mathrm{~mm}$ has $C_{d}$ of 0.323 and $F_{d}$ of $9.06 N . C_{d}$ and $F_{d}$ at a given velocity in Trans critical region remains almost same. But the $\theta$ for $\mathrm{R} 2$ is $108.8^{\circ}$ and $\theta$ for $\mathrm{R} 3$ is $98^{\circ}$. At given velocity, Pressure drag depends on HBL separation angle which means lower the HBL separation angle, higher will be the pressure drag. At same velocity of $40 \mathrm{~m} / \mathrm{s}$ (e.g.), pressure drag force is lower for Rough sphere with less roughness $R_{2}$ than that of rough sphere with high roughness $\mathrm{R}_{3}$. Therefore, at given velocity in supercritical region, increasing surface roughness reduces the $\theta$ and increases the pressure drag. As the HBL separates quickly from the surface, the friction drag force reduces with increase in Roughness. Despite of increasing surface roughness, the combined effect of increased Pressure drag and reduced friction drag maintains the total Drag force to be almost constant in supercritical flow region.

\section{B. Influence of Surface Roughness on Brazuca}

Fig. 9 shows the variation of drag force with flow velocity at different surface roughness for Brazuca Football. Roughness values of $0.11 \mathrm{~mm}$ and $0.55 \mathrm{~mm}$ are considered for the study.

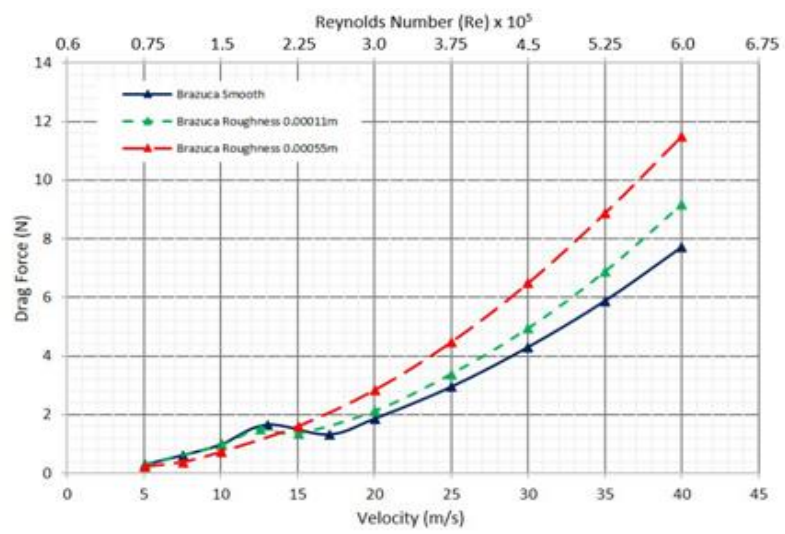

Fig 9:- Drag Force versus Velocity of Brazuca with different surface roughness

Smooth Brazuca lies in laminar regime up to $13 \mathrm{~m} / \mathrm{s}$ and becomes turbulent after $18 \mathrm{~m} / \mathrm{s}$. Critical Re for smooth Brazuca is about $2.72 \times 10^{5}$ and $C_{d}$ at critical $R e$ is 0.190 . Increasing surface roughness reduces Critical Re showing similar effects as in the case of the smooth sphere. Compared to drag force acting on smooth Brazuca, increasing surface roughness decreases the drag force in velocity range of 5 to $15 \mathrm{~m} / \mathrm{s}$ and increases the drag force in range of 17.5 to $40 \mathrm{~m} / \mathrm{s}$.

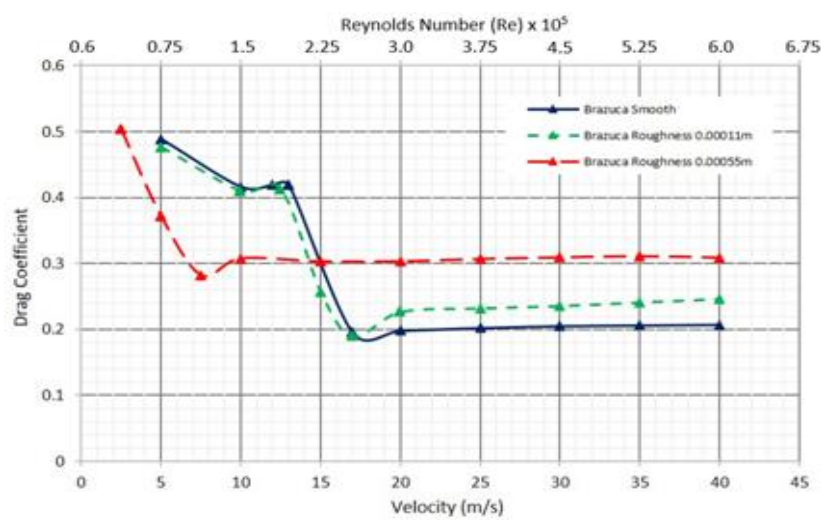

Fig 10:- Drag Coefficient versus Velocity of Brazuca with different surface roughness 
From Fig. 10 it is observed that increasing roughness widens the turbulent region in range of 5 to $40 \mathrm{~m} / \mathrm{s}$. In football the velocity range varies from 15 to $40 \mathrm{~m} / \mathrm{s}$ considering free kicks and maximum velocity recorded in the game. If the football lies in laminar or transition region in this velocity range, at lower spin velocities there is unsymmetrical HBL separation as HBL is laminar on one side and Turbulent on other side resulting in unpredictable path of the ball, also known as Knuckling effect. Let $\mathrm{V}_{\text {spin }}=$ $\mathrm{r} \omega$ be the spinning velocity (say in counterclockwise direction) and $\mathrm{V}$ is the velocity of football corresponding to critical $\mathrm{R}_{\mathrm{e}}$. The resultant velocity on top of football is $\mathrm{V}+$ $\mathrm{V}_{\text {spin }}$ with turbulent HBL and resultant velocity on bottom side is $\mathrm{V}-\mathrm{V}_{\text {spin }}$ with Laminar HBL. Flow separation becomes unsymmetrical due to different nature of HBL on both sides of football which causes unpredictable flight trajectory. To prevent these effects, surface roughness is provided to footballs to ensure than entire velocity range lies in turbulent regime.

\begin{tabular}{|c|c|c|}
\hline & $\begin{array}{c}\text { Critical } \\
\text { Reynolds } \\
\text { Number, } \mathbf{R}_{\mathbf{e}}\end{array}$ & $\begin{array}{c}\text { Critical } \\
\text { Velocity (m/s) }\end{array}$ \\
\hline Brazuca & $2.72 \times 10^{5}$ & 18 \\
\hline $\begin{array}{c}\text { Brazuca Roughness } \\
0.11 \mathrm{~mm}\end{array}$ & $2.55 \times 10^{5}$ & 17 \\
\hline $\begin{array}{c}\text { Brazuca Roughness } \\
0.55 \mathrm{~mm}\end{array}$ & $1.125 \times 10^{5}$ & 7.5 \\
\hline
\end{tabular}

Table 2:- Variation of Critical Re of Brazuca with its Roughness

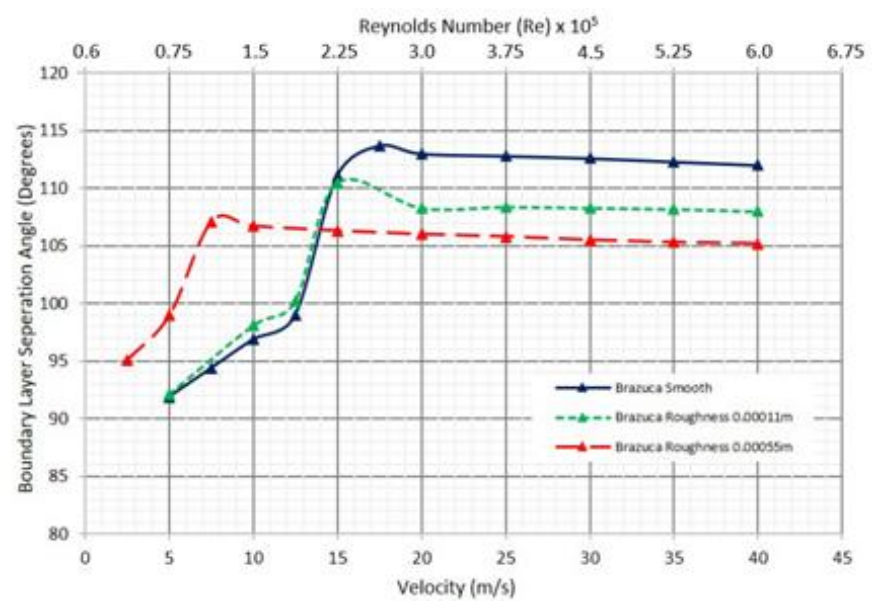

Fig 11:- HBL Separation Angle versus Velocity of Brazuca with different surface roughness

Fig. 11 shows the variation of boundary layer separation angle with respect to velocity of football at surface roughness values of $0 \mathrm{~mm}, 0.11 \mathrm{~mm}, 0.55 \mathrm{~mm}$. The first observation from this graph is that the $\theta$ of Brazuca ball in laminar flow regime is greater $\left(92^{\circ}\right)$ than the $\theta$ is (about $83.6^{\circ}$ ) in laminar flow in case of sphere. For sphere, the $\theta$ does not vary with velocity and remains constant in laminar region whereas for Brazuca, the $\theta$ is increasing gradually in laminar region followed by sharp rise in $\theta$ in transition. The $\theta$ reaches maximum value at the end of transition region when the flow becomes turbulent. The Re corresponding to maximum $\theta$ matches with the critical $\mathrm{Re}$ from $C_{d}$ graph. At critical $R e$, the maximum value of $\theta$ represents delay in HBL separation which minimizes the wake region thereby decreasing pressure drag which in turn reduces overall drag coefficient. This can be observed from $C_{d}$ graph that the minimum value of $C_{d}$ occurs at critical $R e$ corresponding to maximum value of $\theta$. At Re greater than critical Re, $\theta$ decreases slowly in trans critical region and remains almost constant in supercritical region. The reason behind the decrease in $\theta$ after Critical $\mathrm{Re}$ is same as explained for sphere. At Re greater than Critical Re, inertia forces dominate the other forces and energy lost by HBL due to flow against the surface irregularities and formation of eddies at interaction of HBL and surface causes the HBL to lose energy and separates quickly from the surface due to adverse pressure gradient despite of surface irregularities holding the HBL to the surface. This decrease in $\theta$ causes the drag coefficient to increase in trans critical region as the pressure drag increases with decrease in $\theta$. The maximum $\theta$ is $113.7^{\circ}$ at $17.8 \mathrm{~m} / \mathrm{s}$ for smooth Brazuca, $111^{\circ}$ at $16 \mathrm{~m} / \mathrm{s}$ for $0.11 \mathrm{~mm}$ rough Brazuca, $107.8^{\circ}$ at $8 \mathrm{~m} / \mathrm{s}$ for $0.55 \mathrm{~mm}$ rough Brazuca. The maximum $\theta$ decreases with increase in surface roughness. The separation angle curve of smooth Brazuca lies above $R_{1}$ curve which is above the $R_{2}$ curve in turbulent regime. The higher the surface roughness, the lower the $\theta$ in Turbulent region. In the laminar velocity range of smooth Brazuca from 5 to $12.5 \mathrm{~m} / \mathrm{s}$, increasing Roughness delays the HBL separation, increasing $\theta$ and therefore lowers the drag coefficient. This can be observed in $\mathrm{C}_{\mathrm{d}}$ graph.

\section{Influence of Shape and Number of Panels}

FIFA footballs are made up of number of panels assembled together by thermal bonding and they differ in shape from an ideal sphere. The difference in shape of footballs, panel shape, number of panels and orientation of these panels influence the aerodynamic performance of football. The behavior of standard 32-panel football and 6panel Brazuca ball are compared with the performance of smooth sphere in following graphs. No external surface roughness is applied to the 32-panel ball and Brazuca in simulation to eliminate the additional influence of surface roughness.

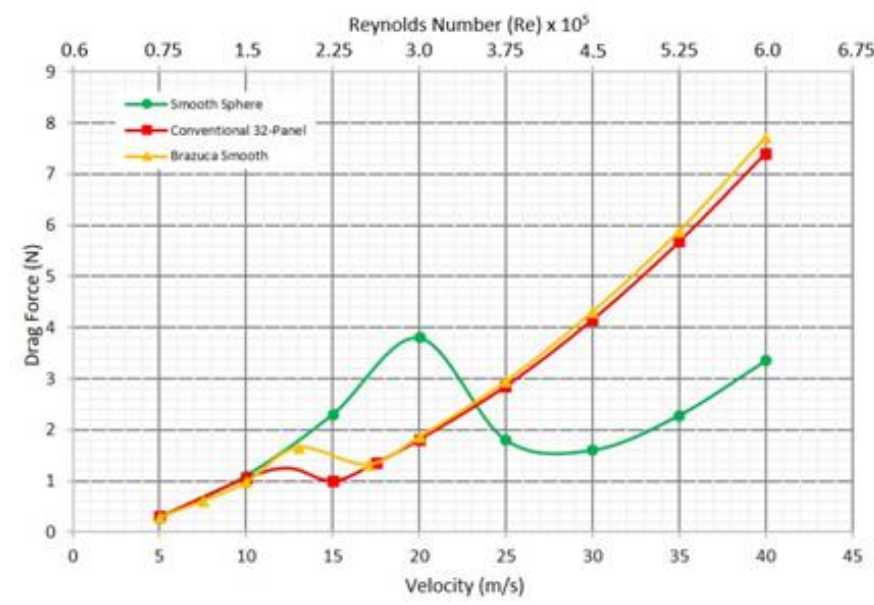

Fig 12:- Drag Force versus Velocity of Smooth Sphere, 32 Panel Ball, Brazuca without surface roughness 
The influence of above parameters on drag force is negligible for laminar flow around the football. Up to $10 \mathrm{~m} / \mathrm{s}$ both the balls have drag force equal to the Drag force of sphere. At velocities above $10 \mathrm{~m} / \mathrm{s}$ the drag force curve of football deviates from that of smooth sphere. In velocity range of 10 to $23 \mathrm{~m} / \mathrm{s}$, the drag force experienced by 32 panel football is less than the drag force of sphere at all velocities in this range. For the velocities above $23 \mathrm{~m} / \mathrm{s}$, the 32-panel football experiences higher drag force compared to sphere.

The drag force curve of Brazuca deviates from that of the sphere at velocity of $12.5 \mathrm{~m} / \mathrm{s}$. The drag force experienced by Brazuca and 32-panel ball is low compared to that of sphere for velocities in range of 12.5 to $23 \mathrm{~m} / \mathrm{s}$. This drag force graph looks similar to Fig. 5 showing effect of surface roughness on drag force. In Turbulent regime, 32-panel ball and Brazuca perform consistently so that the drag force curves of both the balls remains very close to each other. There is variation in the velocities at which the transition starts from laminar to turbulent flow.

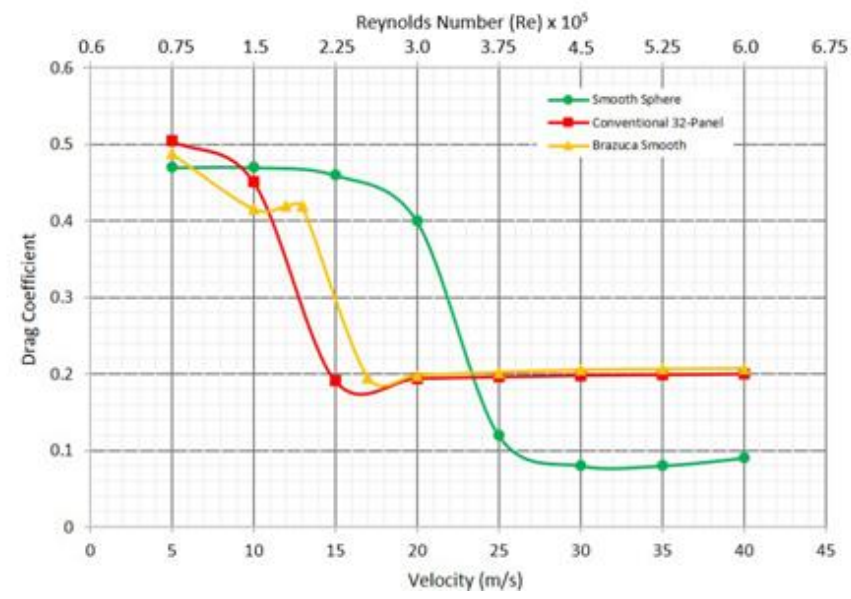

Fig 13:- Drag Coefficient versus Velocity of Smooth Sphere, 32-Panel Ball, Brazuca without surface roughness

\begin{tabular}{|c|c|c|}
\hline & $\begin{array}{c}\text { Critical } \\
\text { Reynolds } \\
\text { Number, } \mathbf{R}_{\mathbf{e}}\end{array}$ & $\begin{array}{c}\text { Critical } \\
\text { Velocity (m/s) }\end{array}$ \\
\hline $\begin{array}{c}\text { Smooth Sphere } \\
\text { Conventional 32-Panel } \\
\text { Ball }\end{array}$ & $2.2 \times 10^{5}$ & 28 \\
\hline Brazuca & $2.72 \times 10^{5}$ & 16.5 \\
\hline
\end{tabular}

Table 3:- Critical Re of Sphere, Conventional 32-Panel Ball, Brazuca

From Fig. 13, it is observed that the critical $\mathrm{Re}$ is different for 32-panel football, Brazuca and smooth sphere. The conventional 32 panel football has critical Re of $2.5 \times$ $10^{5}$. It has laminar HBL up to $10 \mathrm{~m} / \mathrm{s}$ followed by transition region from 10 to $16.5 \mathrm{~m} / \mathrm{s}$. For velocities greater than 16.5 $\mathrm{m} / \mathrm{s}$, the flow around football becomes turbulent. For Brazuca, the critical Re is $2.7 \times 10^{5}$. Brazuca has laminar HBL up to velocity of $13 \mathrm{~m} / \mathrm{s}$ and it undergoes Transition from 13 to $18 \mathrm{~m} / \mathrm{s}$. For velocities above the Critical velocity of $18 \mathrm{~m} / \mathrm{s}$, the HBL becomes Turbulent. The $\mathrm{C}_{\mathrm{d}}$ values of both the balls increases slightly in Trans critical region and remains constant in supercritical region. The $C_{d}$ curves of 32-panel ball and Brazuca remains identical in turbulent regime. The similar Aerodynamic behavior of 32-panel ball and Brazuca is suggested by Drag force graph and $C_{d}$ graph in turbulent flow regime.

The seam length of panels and depth of seam acts as equivalent surface roughness. Decrease in number of panels reduces the seam length. The 32-panel football has seam length of $384 \mathrm{~cm}$ and seam depth of $1.08 \mathrm{~mm}$ whereas the 6-panel thermally bonded Brazuca has seam length of 332 $\mathrm{cm}$ with seam depth of $1.58 \mathrm{~mm}$. From graph 2 , it is concluded that increasing Roughness decreases the critical Re. From above $C_{d}$ graph, 32-panel ball has low critical $R e$ than that of Brazuca implying that the equivalent roughness is higher for 32 panel ball than Brazuca. The seam length of 32-panel ball is $15.6 \%$ larger than the seam length of Brazuca but the seam depth of Brazuca is 50\% larger than the seam depth of 32-panel ball. The combined effect of seam length and seam depth causes the football to have higher equivalent roughness than that of Brazuca. The effect of external surface roughness has additional influence on Aerodynamic performance besides the equivalent roughness caused by panel shape, seam length and depth. The 2014 World cup football Brazuca has external surface roughness added intentionally in order to increase overall equivalent roughness to that of 32-panel ball. This helps to match the Aerodynamic performance of Brazuca with that of 32-panel ball to maintain consistency among players. Comparing $\mathrm{C}_{\mathrm{d}}$ graphs of smooth 32-panel ball and Brazuca with $0.11 \mathrm{~mm}$ roughness, it is observed that the critical $\mathrm{Re}$ is same for both the balls.

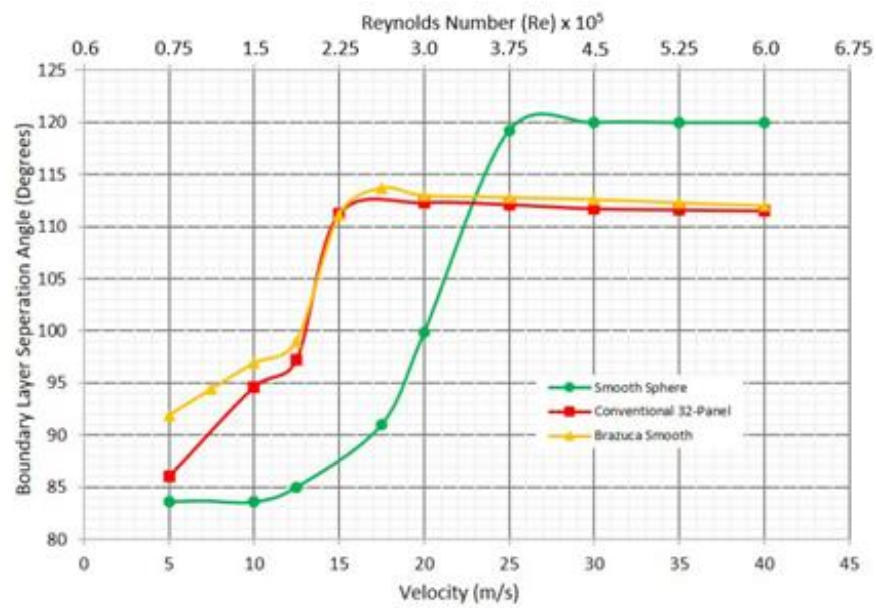

Fig 14:- HBL Separation Angle versus Velocity of Smooth Sphere, 32-Panel Ball, Brazuca without surface roughness

Fig. 14 shows the variation of HBL separation angle with velocity for smooth Sphere, 32-panel ball and Brazuca. No external surface roughness is applied to these balls. For laminar flow around Smooth Sphere, the $\theta$ remains almost constant and in transition flow, $\theta$ increases. But $\theta$ of 32-panel ball and Brazuca increases gradually in laminar flow, followed by drastic increase in $\theta$ in Transition flow. In turbulent regime, all the 3 balls behave identically. In Turbulent HBL, the value of $\theta$ reaches maximum value at critical Re, followed by slight decrease in Trans critical 
region and remains constant in supercritical region. Maximum $\theta$ and critical velocity for smooth sphere, Brazuca, 32-panel ball are $120^{\circ}$ at $27 \mathrm{~m} / \mathrm{s}, 113.8^{\circ}$ at $18 \mathrm{~m} / \mathrm{s}$, $112^{\circ}$ at $16 \mathrm{~m} / \mathrm{s}$ respectively. The value of $\theta$ in Turbulent flow regime is in order of smooth sphere, Brazuca, Football with maximum $\theta$ for sphere and minimum $\theta$ for 32-panel ball. From Fig. 21 it is observed that increase in surface roughness reduces the value of $\theta$ in Turbulent flow region. This implies that the 32-panel ball has higher equivalent roughness than that of Brazuca if external surface roughness is not considered. The same conclusion is suggested by $\mathrm{C}_{\mathrm{d}}$ graph. From the above graph, the behavior of 32-panel ball and Brazuca is identical in Turbulent region.

\section{Influence of Panel Orientation on Teamgeist}

The Teamgeist has 14 panels with two different panel shapes. As the panels differ in shape and size, the amount of surface roughness varies on different parts of the ball. To study the variation of Flight characteristics with respect to Orientation of panels, Teamgeist is selected. The behavior of Teamgeist is analyzed at three orientations of $0^{\circ}, 45^{\circ}$ and $90^{\circ}$. The Drag force and $\mathrm{C}_{\mathrm{d}}$ curve at $45^{\circ}$ orientation deviates from that of $0^{\circ}$ orientation. There is significant variation in Aerodynamic behavior of Teamgeist at $45^{\circ}$ compared to the behavior at $0^{\circ}$. As per the CFD results obtained, Teamgeist shows no noticeable difference in its performance at $0^{\circ}$ and $90^{\circ}$ orientations. For velocities up to $15 \mathrm{~m} / \mathrm{s}$, the influence of panel orientation on drag force is negligible. Teamgeist experience lesser Drag force at $45^{\circ}$ orientation than the drag force at $0^{\circ}$ and $90^{\circ}$ orientation for velocities above $15 \mathrm{~m} / \mathrm{s}$. From Fig. 22 it is observed that the critical Re is also influenced by panel orientation.

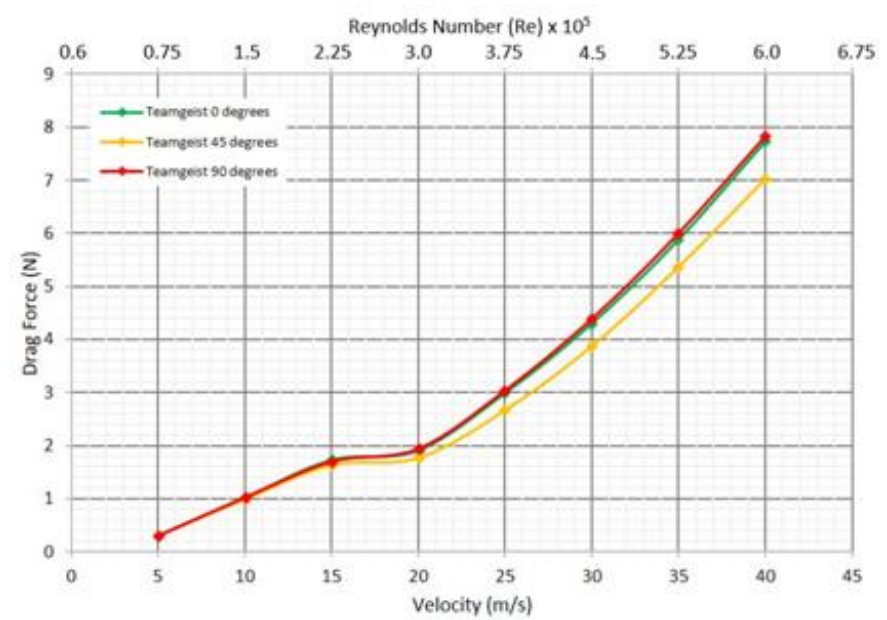

Fig 15:- Drag Force versus Velocity of Teamgeist with different panel orientation

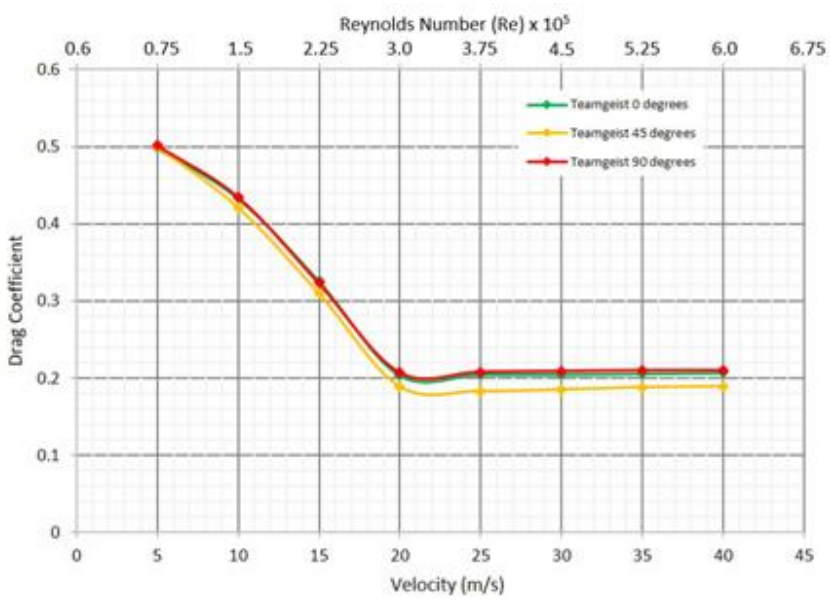

Fig 16:- Drag Coefficient versus Velocity of Teamgeist with different panel orientation

\begin{tabular}{|c|c|c|}
\hline & $\begin{array}{c}\text { Critical } \\
\text { Reynolds } \\
\text { Number, } \mathbf{R}_{\mathbf{e}}\end{array}$ & $\begin{array}{c}\text { Critical } \\
\text { Velocity }(\mathbf{m} / \mathbf{s})\end{array}$ \\
\hline${\text { Teamgeist } 0^{\circ}}^{\circ}$ & $2.48 \times 10^{5}$ & 16.54 \\
\hline${\text { Teamgeist } 45^{\circ}}^{\circ}$ & $2.55 \times 10^{5}$ & 17 \\
\hline${\text { Teamgeist } 90^{\circ}}^{\circ}$ & $2.48 \times 10^{5}$ & 16.54 \\
\hline
\end{tabular}

Table 4:- Variation of Critical Re of Teamgeist with Panel Orientation

Critical $\operatorname{Re}$ at $45^{\circ}$ orientation is greater than that at $0^{\circ}$ and $90^{\circ}$ orientation. This implies that the flow around Teamgeist at $45^{\circ}$ orientation becomes Turbulent at higher velocity as this panel orientation offers lesser surface roughness compared to other two orientations. This is also suggested by the less value of $\mathrm{Cd}$ at $45^{\circ}$ orientation.

From the Fig. 17 the value of $\theta$ varies drastically if the orientation of panels is varied. This is due to the variation in position of seams from stagnation point. The $\theta$ is influenced by panel orientation in the entire velocity range in both laminar and turbulent region. It is to be noticed that the $\mathrm{HBL}$ separation curves are different at $0^{\circ}$ and $90^{\circ}$ orientations but the $\mathrm{C}_{\mathrm{d}}$ graphs for these orientations remains identical. HBL Separation angle varies in different planes at a given orientation of football.

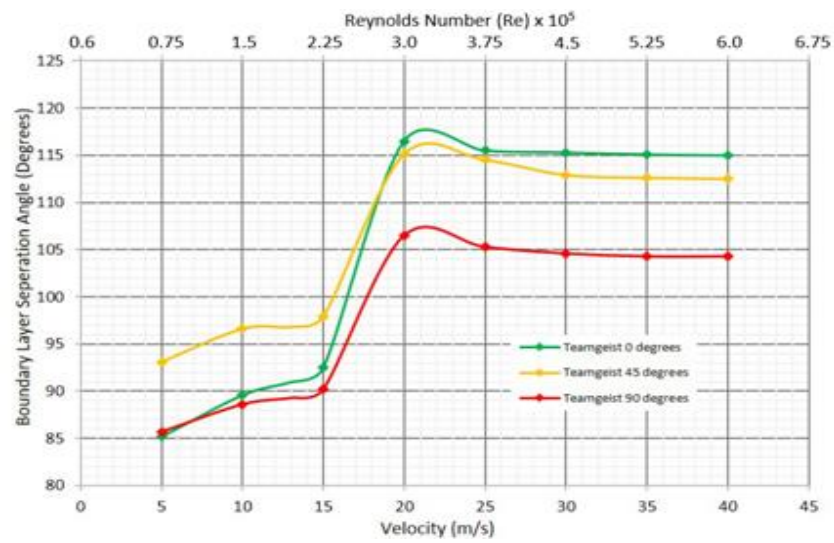

Fig 17:- HBL Separation Angle versus Velocity of Teamgeist with different panel orientation 
ISSN No:-2456-2165

The HBL separation angles in Fig. 17 are measured in $\mathrm{X}-\mathrm{Z}$ plane. At $0^{\circ}$ orientation the $\theta$ is $115.5^{\circ}$ in $\mathrm{X}-\mathrm{Z}$ plane and $106.7^{\circ}$ in $\mathrm{Y}-\mathrm{Z}$ plane at velocity of $25 \mathrm{~m} / \mathrm{s}$. The drastic variation in $\theta$ is due to relative location of panel seams from the stagnation point. The presence of seams disturbs the flow and influence the $\theta$. The HBL separation angle depends on the plane in which it is measured but the drag force acts on the entire football which depends on panel orientation. This is the reason for identical values of $\mathrm{C}_{\mathrm{d}}$ for $0^{\circ}$ and $90^{\circ}$ orientations at given velocity.

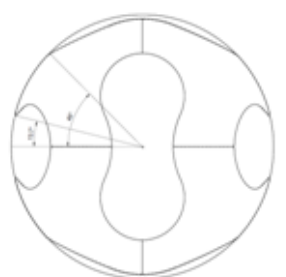

(a) Teamgeist $0^{\circ}$ Orientation

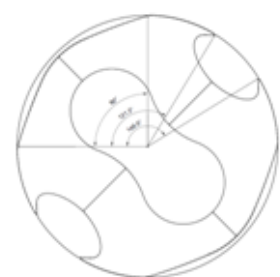

(b) Teamgeist $45^{\circ}$ Orientation

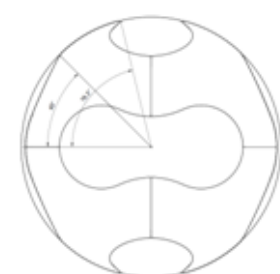

(c) Teamgeist $90^{\circ}$ Orientation
Fig 18:- Location of Seams on Teamgeist at different orientations

Seam is referred to as the joining between two panels of a football. The streamlines flowing over a football have to move over two types of seams. The seam might be either along the direction of streamline or perpendicular to the direction of streamline, which is referred as cross seam. The relative location of seam is measured from the stagnation point.

At $0^{\circ}$ orientation of Teamgeist, the cross seams are located at $45^{\circ}$ and $135^{\circ}$ spacing $90^{\circ}$ apart and the value of $\theta$ is $115.3^{\circ}$ at $30 \mathrm{~m} / \mathrm{s}$. As the seams are spaced apart, the seams have negligible influence on separation angle. At $45^{\circ}$ orientation, the cross seams are located at $90^{\circ}$ and $121.3^{\circ}$ which are $31.3^{\circ}$ apart with a seam along the direction of streamline in between the cross seams. The value of $\theta$ at this orientation is $112.9^{\circ}$. The $2^{\text {nd }}$ seam located at $121.3^{\circ}$ has no influence on HBL separation as the HBL separates before this seam. The cross seam at $90^{\circ}$ and seam along the streamlines acts as surface roughness and decreases the $\theta$ due to energy lost by HBL to flow against the seams causing flow perturbation so the HBL separates quickly. At $90^{\circ}$ orientation, the cross seams are at $76.3^{\circ}$ and $103.7^{\circ}$ which are $27.4^{\circ}$ apart and the corresponding $\theta$ is $104.6^{\circ}$ just after the location of $2^{\text {nd }}$ seam. As the cross seams are located very close to each other, they have greater influence on HBL separation. From Fig. 19, the variation in HBL separation angle and size of wake region with respect to panel orientation of Teamgeist can be observed. The size of the wake is larger at $90^{\circ}$ orientation and narrow wake is observed at $0^{\circ}$ orientation.

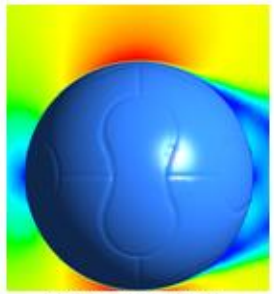

(a) Teamgeist $0^{\circ}$ Orientation

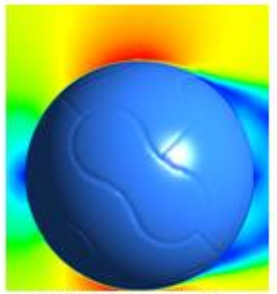

(a) Teamgeist $45^{\circ}$ Orientation

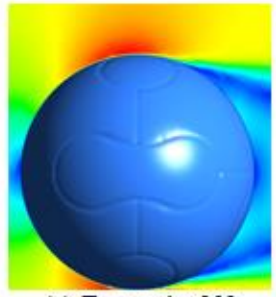

(a) Teamgeist $90^{\circ}$ Orientation
Fig 19:- Velocity Profiles of Teamgeist showing HBL Separation at different panel orientations

\section{E. Influence of Panel Orientation on Brazuca}

Brazuca differs from Teamgeist in number of panels and panel shape. Brazuca has 6 panels of same shape whereas Teamgeist has 14 panels with two different shaped panels. The variation in Aerodynamic behavior of Brazuca is studied by simulating two orientations, $0^{\circ}$ and $45^{\circ}$ at a velocity of $25 \mathrm{~m} / \mathrm{s}$. The streamlines in these two orientations looks identical. The drag force and Separation angle at $0^{\circ}$ orientation are $2.923 \mathrm{~N}$ and $112.7^{\circ}$ and at $90^{\circ}$ orientation are $2.939 \mathrm{~N}$ and $113^{\circ}$. From Fig. 20, The variation in velocity profiles with panel orientation is negligible. From these results, it is observed that the influence of panel orientation is negligible on Flight characteristics of Brazuca. The panels of Brazuca are designed in such a way that the flight trajectory of Brazuca is predictable and is independent of panel orientation.

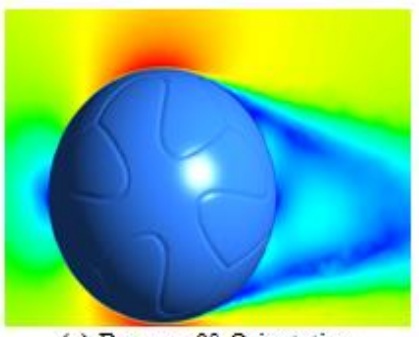

(a) Brazuca $0^{\circ}$ Orientation

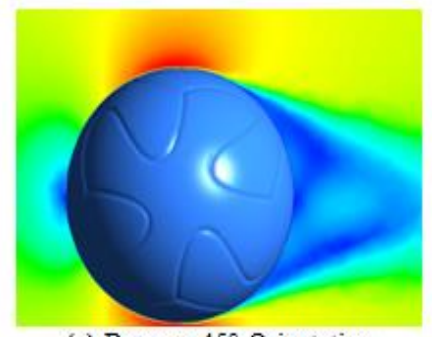

(a) Brazuca $45^{\circ}$ Orientation
Fig 20:- Velocity Profiles of Brazuca showing HBL Separation at different panel orientations

\section{F. Influence of Seam length on Critical Reynolds Number}

The line shown in the Fig. 21 is obtained by linear regression of Critical $\mathrm{Re}$ and Total seam lengths of 32 panel ball, Brazuca and Teamgeist. The critical Re of conventional 32-panel ball, Teamgeist and Brazuca are plotted against their respective seam lengths. The conventional 32-panel football has seam Length of $3.84 \mathrm{~m}$ and critical Re of $2.47 \times 10^{5}$. 


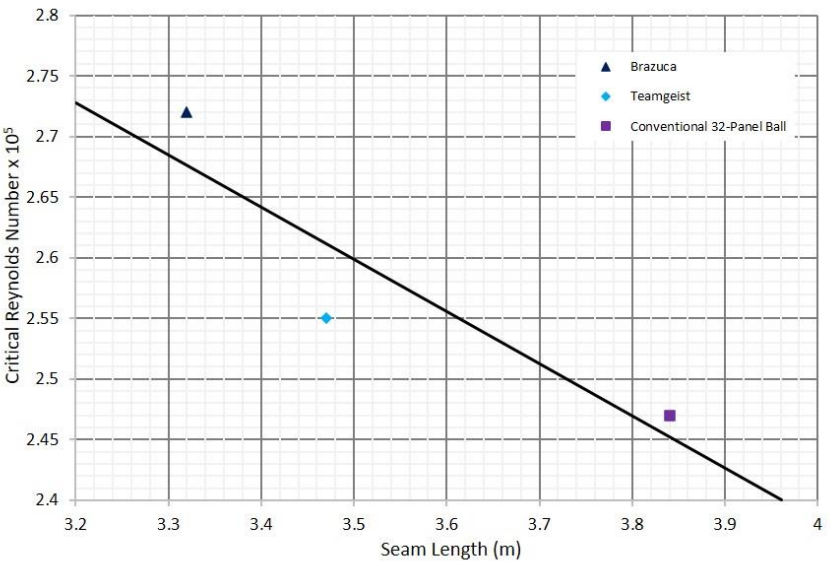

Fig 21:- Variation of Critical Re with Seam length

The 14 panel Teamgeist has seam length of $3.47 \mathrm{~m}$ and critical $\operatorname{Re}$ of $2.55 \times 10^{5}$ at $45^{\circ}$ panel orientation whereas the 6-panel Brazuca has total seam length of 3.32 $\mathrm{m}$ and critical $\operatorname{Re}$ of $2.72 \times 10^{5}$. The values of Critical Re are obtained with zero surface roughness so that the additional effect of panel Roughness on critical Re is not considered. The influence of the effective roughness caused by the seam length on critical Re is studied in this graph. Decreasing the number of panels reduces the total seam length thereby reducing the effective surface roughness resulting in higher critical Re. The linear regression fit between the critical $\mathrm{Re}$ values of these 3 balls shows that the increase in seam length reduces the critical Re.

\section{G. Combined Effect of Panel Orientation and Surface Roughness effect on Teamgeist}

Teamgeist shows the variation in the HBL Separation when the orientation of panels changed. Fig. 22 shows the combined effect of Surface Roughness and panel orientation on the HBL separation angle of Teamgeist using Surface Roughness values of $0.11 \mathrm{~mm}$ and $0.55 \mathrm{~mm}$ and these results are compared with Smooth Teamgeist. The values of $\theta$ are obtained at flow velocity of $25 \mathrm{~m} / \mathrm{s}$ with flow having $\operatorname{Re}$ of $3.75 \times 10^{5}$ which is greater than the critical Re of Teamgeist so the Teamgeist has Turbulent HBL at $25 \mathrm{~m} / \mathrm{s}$. The results show that the Surface Roughness significantly controls the $\theta$. Smooth Teamgeist shows drastic variation in $\theta$ with panel orientation. Increasing Surface Roughness has two effects. It reduces the $\theta$ making the flow to be turbulent at lower Re, reducing the value of $\theta$ at $25 \mathrm{~m} / \mathrm{s}$ compared to Smooth. This effect is similar to influence of surface roughness on $\theta$ of sphere. Adding Surface Roughness decreases the influence of orientation of panels on $\theta$. The difference between maximum and minimum values of $\theta$ are $10.2^{\circ}$ for smooth panels, $8.3^{\circ}$ for $0.11 \mathrm{~mm}$ rough panels and $4.2^{\circ}$ for 0.55 $\mathrm{mm}$ rough panels. The Teamgeist with $0.55 \mathrm{~mm}$ surface roughness has minimum variation in $\theta$ compared to 0.11 $\mathrm{mm}$ rough and smooth Teamgeist. For smooth Teamgeist, the panels are simulated with zero surface roughness. The seams between the panels acts as Roughness. The overall Roughness is concentrated at seams with smooth panels. Changing the orientation of football changes the orientation of panels and seams which changes the location of concentrated Roughness. Presence of the seams in the vicinity of $\mathrm{HBL}$ separation significantly affects the $\theta$ making the HBL to separate quickly as the effective roughness of seam causes the HBL to lose energy.

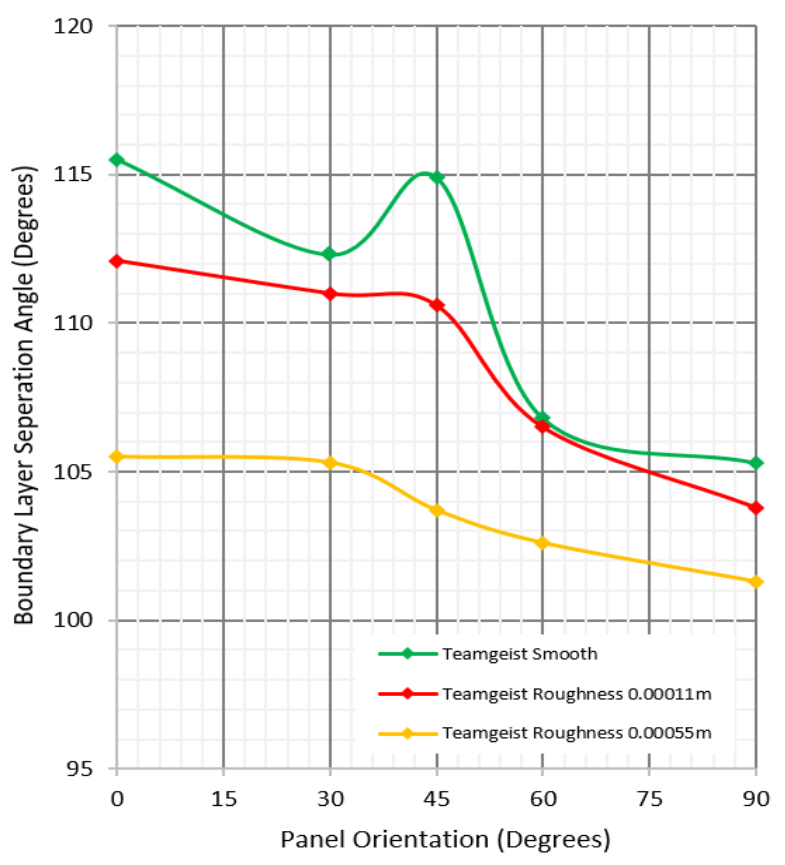

Fig 22:- HBL Separation Angle versus Panel Orientation of Teamgeist with different surface roughness

Using Rough panels allows for the distribution of Surface Roughness at all parts of the football. The Distribution of Roughness over the panels minimizes the influence of concentrated Roughness at seams. Increasing panel Roughness closer to the seam depth value results in uniform surface roughness on all parts of the football eliminating the orientation effects. This can be observed from the above graph in which $0.55 \mathrm{~mm}$ minimizes the orientation effects compared to $0.11 \mathrm{~mm}$ roughness. Therefore, the use of rough panels helps to minimize the knuckling effects by reducing critical $\mathrm{Re}$ ensuring Turbulent HBL in the velocity range of footballs and minimizing the orientation effects so that the flight trajectory of football becomes predictable.

\section{H. Flow Visualization}

The flow of air onto the football is visualized in Ansys Fluent with the aid of streamlines. Streamlines provide an insight to HBL separation, the size of wake region and formation of eddies in the wake region. The 3-dimensional flow field around Conventional 32-panel ball, Teamgeist and Brazuca are represented below using 3D stream lines.

The flow is simulated at velocity of $25 \mathrm{~m} / \mathrm{s}$ at which the flow around Conventional 32-panel ball, Teamgeist and Brazuca is Turbulent. The formation of wake and eddies in wake region can be visualized in the following $3 \mathrm{~d}$ streamlines around these Footballs. The conventional 32panel ball has larger wake region and Brazuca has smaller wake region. 


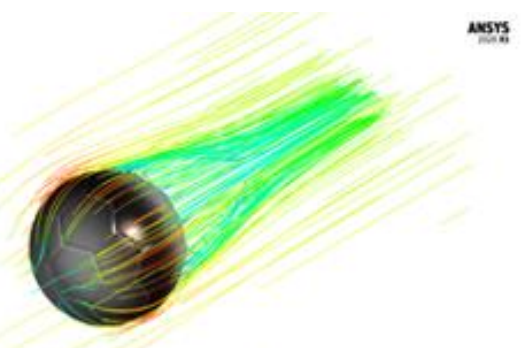

(a) Conventional 32-Panel Football

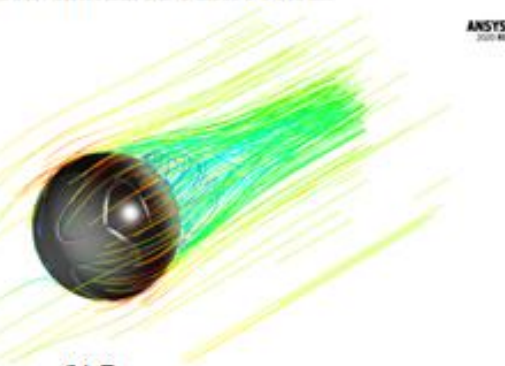

(b) Brazuca

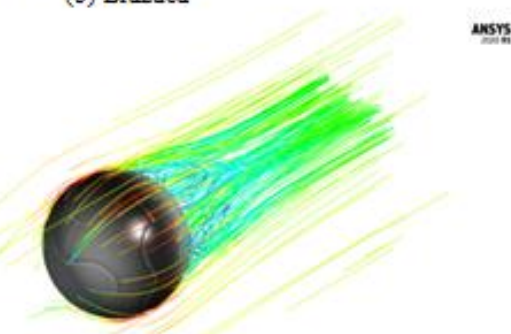

(c) Teamgeist

Fig 23:- Flow Visualization of Footballs

\section{CONCLUSION}

In this study, the influence of the surface roughness, number of panels, seam length and orientation of panels of the football on its aerodynamics and flight characteristics were examined by carrying out numerical simulation using Ansys fluent CFD package on three balls, the conventional 32-panel ball, Teamgeist, Brazuca having different number of panels, panel shape, seam length and surface roughness. The results indicate that the use of rough surfaces on football panels lowers the critical Re causing the flow to become turbulent at lower velocities. Increase in surface roughness increases the drag coefficient and decreases the separation angle in turbulent flow. The maximum value of HBL separation angle is observed at critical Re. The purpose of using surface roughness on panels is to eliminate knuckle ball effects by ensuring that the entire velocity range lies in turbulent region and by minimizing the panel orientation effects on flight characteristics. Using rough surfaces beyond a certain value of roughness does not have noticeable influence on the aerodynamic performance of football.

The seam length and seam depth of panels act as equivalent roughness and has significant influence on flight characteristics. The 32-panel ball has higher equivalent roughness than that of Brazuca as the panel length of football is greater than that of Brazuca. so that the Brazuca is provided with nub texture on surface to increase its overall roughness equal to that of 32 panel ball. Brazuca shows the similar effects as that of a perfect sphere when surface roughness is provided on panels, decreasing the value of critical Re. The location of seams and orientation of panels has influence on the HBL separation angle and Drag force. 6-panel Brazuca shows consistent aerodynamic behavior irrespective of their orientation whereas the 14panel Teamgeist shows significant variation in performance with panel orientation. The combined effect of panel orientation and surface roughness is studied for 14-panel Teamgeist ball. Increasing surface roughness on panels minimizes the effect of panel orientation on HBL separation angle making the flight trajectory of football predictable.

The above conclusions can be used to explain the aerodynamic behavior of the most controversial ball in football history, the Jabulani. The 8 panel Jabulani ball is introduced in South Africa in 2010 World cup with seam length of $1.98 \mathrm{~m}$ and seam depth of $0.48 \mathrm{~mm}$. The seam length of Jabulani is $48.4 \%$ lesser than that of conventional 32 panel ball, $42.9 \%$ lesser than seam length of Teamgeist and $40.36 \%$ lesser than the Brazuca seam length which implies that the Jabulani has less effective roughness compared to Conventional 32-Panel ball, Teamgeist and Brazuca. The critical $\mathrm{Re}$ of Jabulani is higher than the critical Re of other three footballs so that the flow around Jabulani becomes laminar at low velocities and turbulent at higher velocities. At low spin velocities, the HBL remains laminar on one side and Turbulent on other side causing knuckle ball effects. The Jabulani has 8 panels with two different panel shapes. As the panels differ in shape and size, the amount of surface roughness varies on different parts of the ball resulting in significant variation in Aerodynamic performance with respect to panel orientation. The combined effect of higher value of critical $\mathrm{Re}$ and panel orientation effects results in significant knuckling effects making the trajectory of Jabulani unpredictable at low spin velocities. The design of Brazuca is optimized with 6 panels of same shape with increased seam Length and external surface roughness on panels is provided to lower the value of critical $\mathrm{Re}$ and eliminating the panel orientation effects to eliminate knuckling effects resulting in highly predictable flight trajectory of football.

\section{REFERENCES}

[1]. Achenbach, E., 1972: "Experiments on the flow past spheres at very high Reynolds numbers", J. Fluid Mech., 54, pp. 565-575J. Clerk Maxwell, A Treatise on Electricity and Magnetism, 3rd ed., vol. 2. Oxford: Clarendon, 1892, pp.68-73.

[2]. Achenbach, E., 1974a: "The effects of surface roughness and tunnel blockage on the flow past spheres", J. Fluid Mech., 65, pp. 113-125K. Elissa, "Title of paper if known," unpublished.

[3]. Asai, T. \& Seo, K. "Aerodynamic drag of modern soccer balls”. SpringerPlus 2, 171 (2013).M. Young, The Technical Writer's Handbook. Mill Valley, CA: University Science, 1989.

[4]. Alam F, et al. "A comparative study of football aerodynamics". Proc Eng. 2010;2:2443-8. 
[5]. Alam F, et al. "Aerodynamics of contemporary FIFA soccer balls". Proc Eng. 2011;13:188-93.

[6]. Goff JE, Asai T and Hong S. "A comparison of Jabulani and Brazuca non-spin aerodynamics". J Sports Eng Tech 2014; 228: 188-194.

[7]. Goff JE, Asai $\mathrm{T}$ and Hong S. "Aerodynamic and surface comparisons between Telstar 18 and Brazuca". J Sports Eng Tech 2018; DOI: 10.1177/1754337118773214.

[8]. Hong, Sungchan; Asai, Takeshi (29 May 2014). "Effect of panel shape of soccer ball on its flight characteristics". Scientific Reports. 4 (1): 5068. doi:10.1038/srep05068. PMC 4038026. PMID 24875291.

[9]. Goff, J.E.; Smith W.H.; Carré, M.J. "Football boundary-layer separation via dust experiments". Sports Eng. 2011, 14, 139-146.
[10]. Sungchan Hong, John Eric Goff2 and Takeshi Asai "Effect of a soccer ball's surface texture on its aerodynamics and trajectory". Journal of Sports Engineering and Technology . October 2018.DOI: 10.1177/1754337118794561.

[11]. Adrian L. Kiratidis, Derek B. Leinweber, "An Aerodynamic Analysis of Recent FIFA World Cup Balls". arXiv:1710.02784v2 [physics.pop-ph] 18 Feb 2018.

[12]. Harun Chowdhury, "Aerodynamic study of FIFAapproved footballs ".Procedia Engineering 105 ( 2015 ) $317-322$.

[13]. Watts, R.G. and Sawyer, E., 1975. "Aerodynamics of a knuckleball”. Am. J.Physics, 43(11), 960-963.

[14]. M. Official World Cup ball, Jabulani, getting the blame for soft goals - Robert Green - and missed ones. New York Daily News; 14 June 2010.

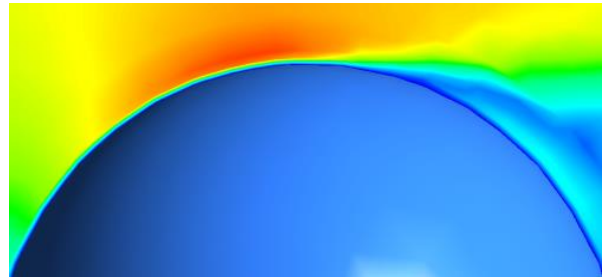

(a) $\mathrm{V}=10 \mathrm{~m} / \mathrm{s}, \mathrm{R}=0 \mathrm{~mm}, \theta=83.6^{\circ}$

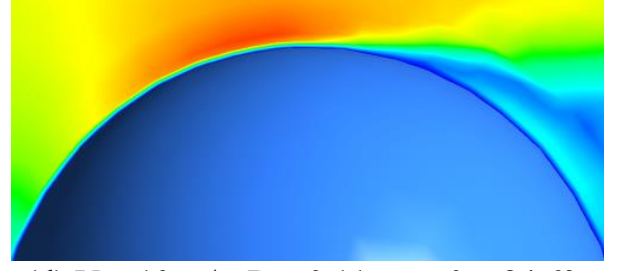

(d) $\mathrm{V}=10 \mathrm{~m} / \mathrm{s}, \mathrm{R}=0.11 \mathrm{~mm}, \theta=84.6^{\circ}$

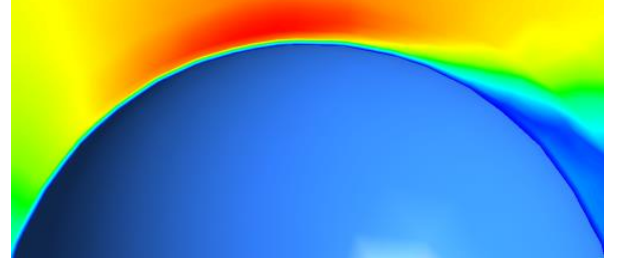

(g) $\mathrm{V}=10 \mathrm{~m} / \mathrm{s}, \mathrm{R}=0.55 \mathrm{~mm}, \theta=116.2^{\circ}$

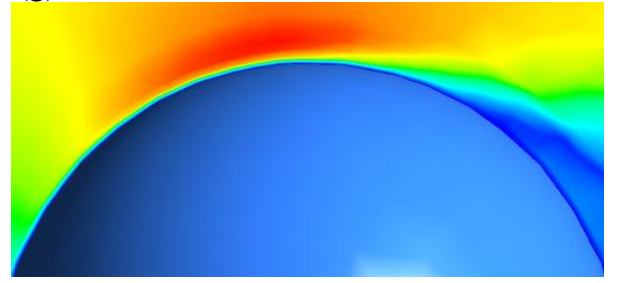

(j) $\mathrm{V}=10 \mathrm{~m} / \mathrm{s}, \mathrm{R}=2.75 \mathrm{~mm}, \theta=101.4^{\circ}$

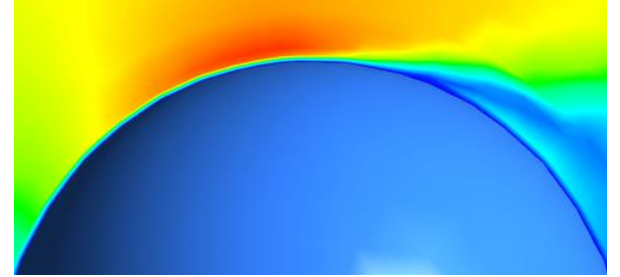

(b) $\mathrm{V}=20 \mathrm{~m} / \mathrm{s}, \mathrm{R}=0 \mathrm{~mm}, \theta=99.8^{\circ}$

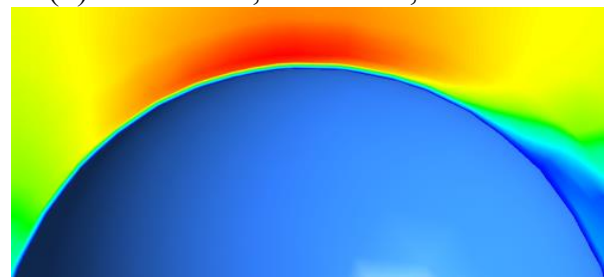

(e) $\mathrm{V}=20 \mathrm{~m} / \mathrm{s}, \mathrm{R}=0.11 \mathrm{~mm}, \theta=118.1^{\circ}$

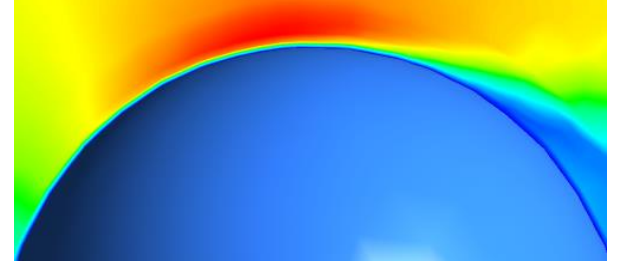

(h) $\mathrm{V}=20 \mathrm{~m} / \mathrm{s}, \mathrm{R}=0.55 \mathrm{~mm}, \theta=110.9^{\circ}$

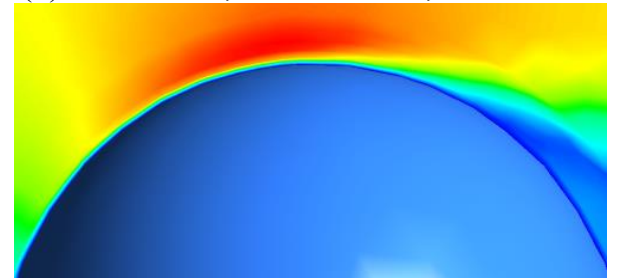

(k) $\mathrm{V}=20 \mathrm{~m} / \mathrm{s}, \mathrm{R}=2.75 \mathrm{~mm}, \theta=100.2^{\circ}$

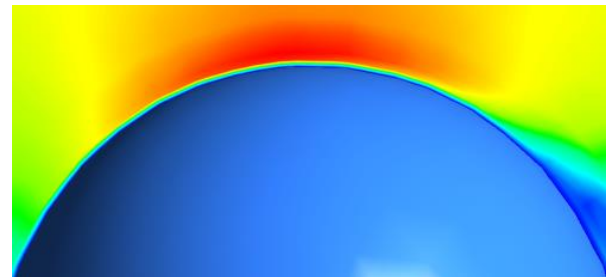

(c) $\mathrm{V}=30 \mathrm{~m} / \mathrm{s}, \mathrm{R}=0 \mathrm{~mm}, \theta=120^{\circ}$

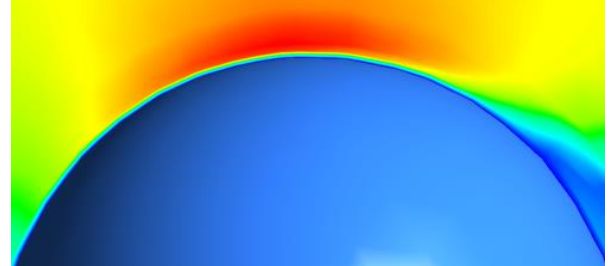

(f) $\mathrm{V}=30 \mathrm{~m} / \mathrm{s}, \mathrm{R}=0.11 \mathrm{~mm}, \theta=117.2^{\circ}$

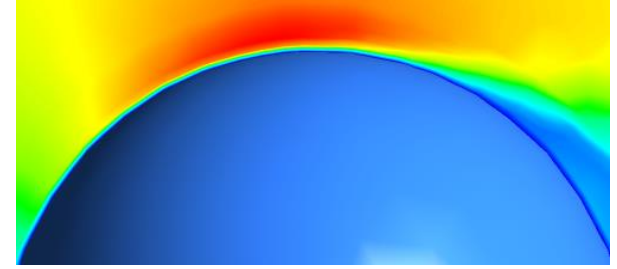

(i) $\mathrm{V}=30 \mathrm{~m} / \mathrm{s}, \mathrm{R}=0.55 \mathrm{~mm}, \theta=109^{\circ}$

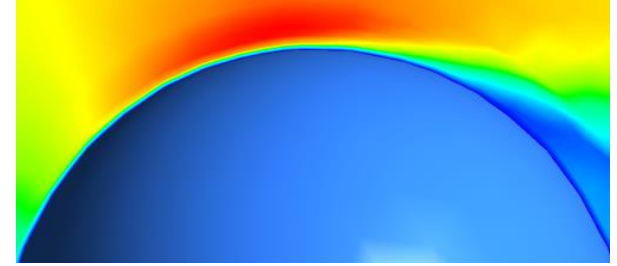

(1) $\mathrm{V}=30 \mathrm{~m} / \mathrm{s}, \mathrm{R}=2.75 \mathrm{~mm}, \theta=98.6^{\circ}$

Fig 24:- shows the velocity profiles of Sphere at different surface roughness to analyze the HBL Separation Angle 


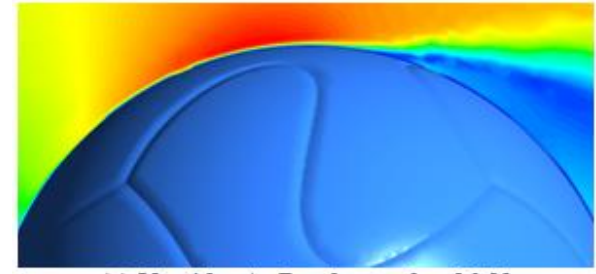

(a) $\mathrm{V}=10 \mathrm{~m} / \mathrm{s}, \mathrm{R}=0 \mathrm{~mm}, \theta=96.9^{\circ}$

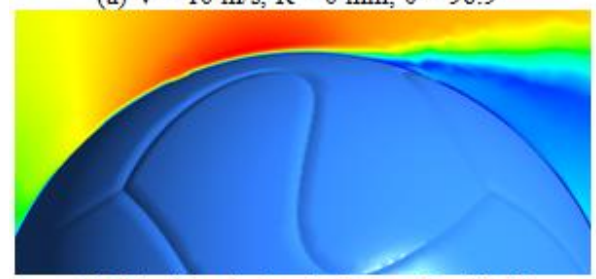

(d) $\mathrm{V}=10 \mathrm{~m} / \mathrm{s}, \mathrm{R}=0.11 \mathrm{~mm}, \theta=98.1^{\circ}$

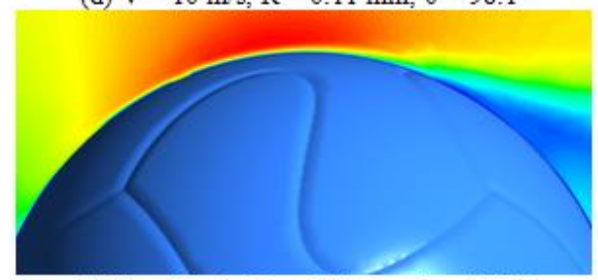

(g) $\mathrm{V}=10 \mathrm{~m} / \mathrm{s}, \mathrm{R}=0.55 \mathrm{~mm}, \theta=106.7^{\circ}$

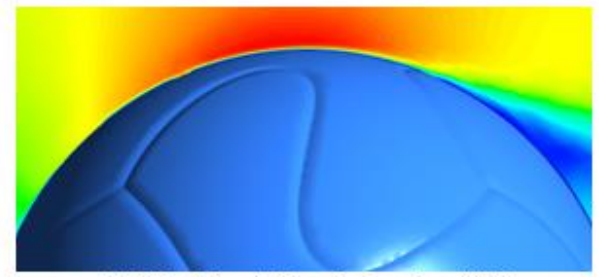

(b) $\mathrm{V}=20 \mathrm{~m} / \mathrm{s}, \mathrm{R}=0 \mathrm{~mm}, \theta=113^{\circ}$

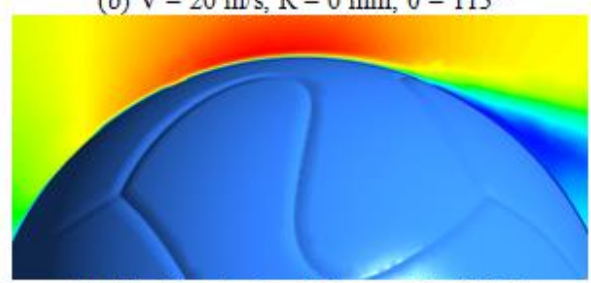

(e) $\mathrm{V}=20 \mathrm{~m} / \mathrm{s}, \mathrm{R}=0.11 \mathrm{~mm}, \theta=108.3^{\circ}$

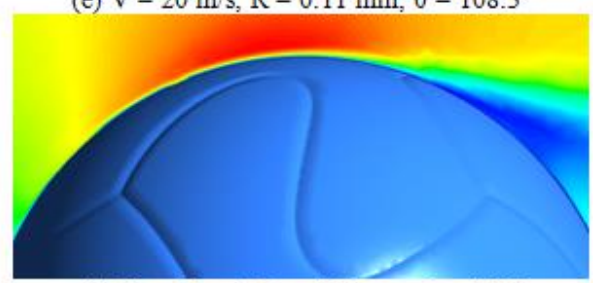

(h) $\mathrm{V}=20 \mathrm{~m} / \mathrm{s}, \mathrm{R}=0.55 \mathrm{~mm}, \theta=106^{\circ}$

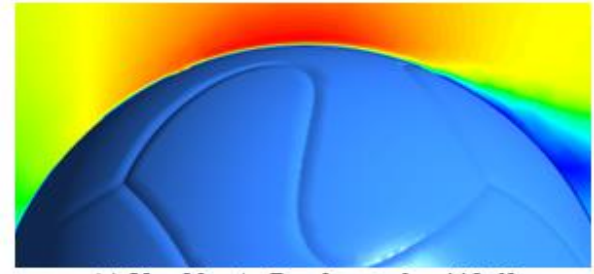

(c) $\mathrm{V}=30 \mathrm{~m} / \mathrm{s}, \mathrm{R}=0 \mathrm{~mm}, \theta=112.6^{\circ}$

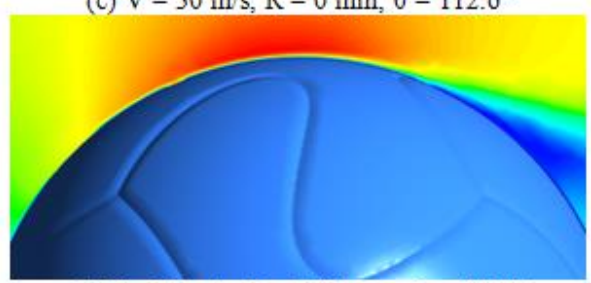

(f) $\mathrm{V}=30 \mathrm{~m} / \mathrm{s}, \mathrm{R}=0.11 \mathrm{~mm}, \theta=108.3^{\circ}$

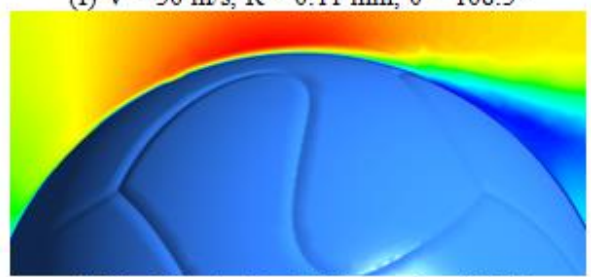

(i) $\mathrm{V}=30 \mathrm{~m} / \mathrm{s}, \mathrm{R}=0.55 \mathrm{~mm}, \theta=105.5^{\circ}$

Fig 25:- shows the velocity profiles of Brazuca at different surface roughness to analyze the HBL Separation Angle

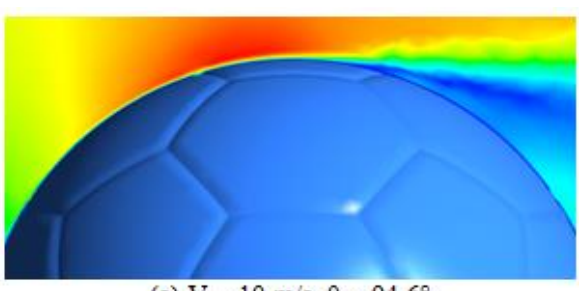

(a) $\mathrm{V}=10 \mathrm{~m} / \mathrm{s}, \theta=94.6^{\circ}$

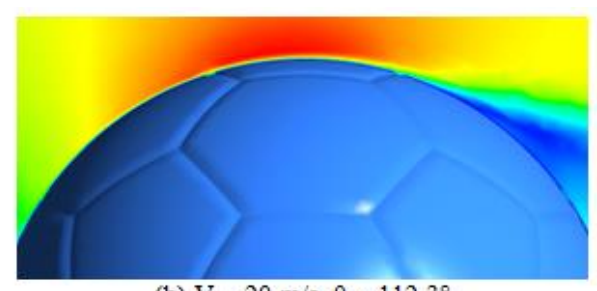

(b) $\mathrm{V}=20 \mathrm{~m} / \mathrm{s}, \theta=112.3^{\circ}$

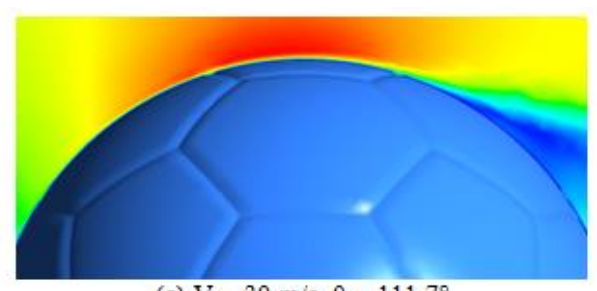

(c) $\mathrm{V}=30 \mathrm{~m} / \mathrm{s}, \theta=111.7^{\circ}$

Fig 26:- shows the velocity profiles of Conventional 32-Panel Ball to analyze the HBL Separation Angle

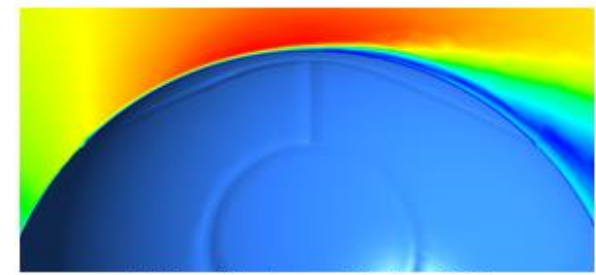

(a) $\mathrm{V}=10 \mathrm{~m} / \mathrm{s}, \varphi=0^{\circ}, \theta=89.6^{\circ}$

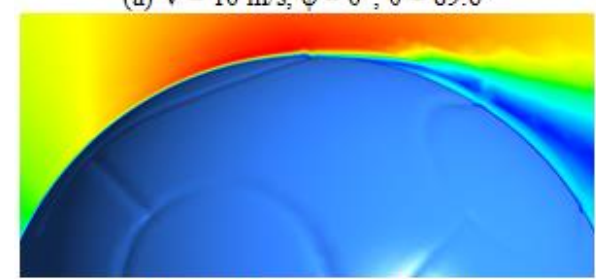

(d) $\mathrm{V}=10 \mathrm{~m} / \mathrm{s}, 0=45^{\circ}, \theta=96.6^{\circ}$

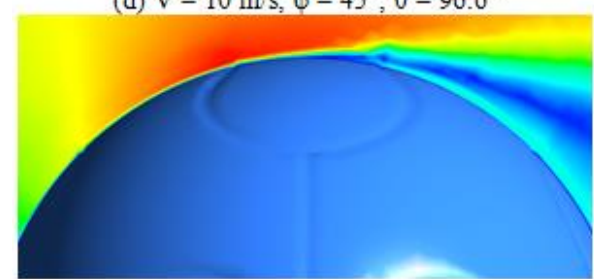

(g) $\mathrm{V}=10 \mathrm{~m} / \mathrm{s}, \varphi=90^{\circ}, \theta=88.6^{\circ}$

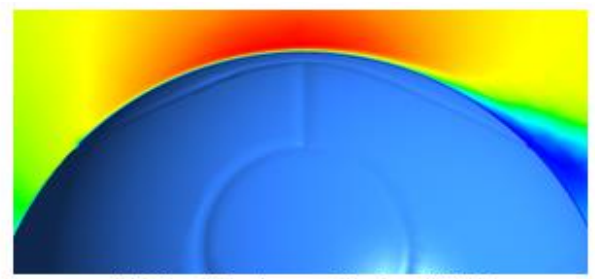

(b) $\mathrm{V}=20 \mathrm{~m} / \mathrm{s}, \varphi=0^{\circ}, \theta=116.5^{\circ}$

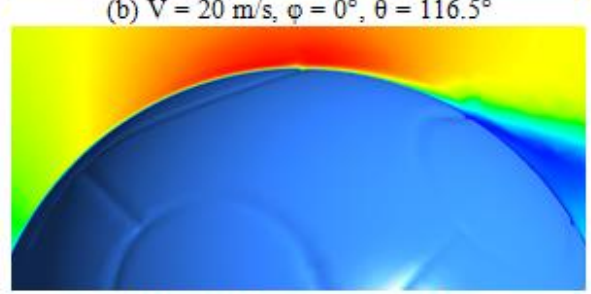

(e) $\mathrm{V}=20 \mathrm{~m} / \mathrm{s}, \mathrm{O}=45^{\circ}, \theta=115.1^{\circ}$

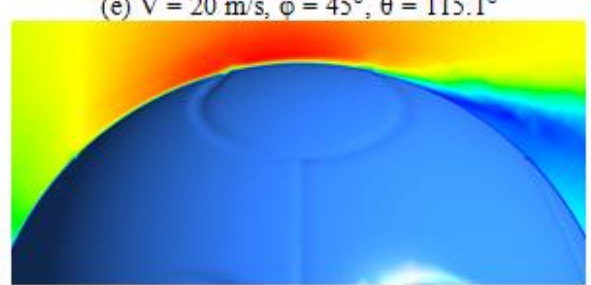

(h) $\mathrm{V}=20 \mathrm{~m} / \mathrm{s}, \mathrm{O}=90^{\circ}, \theta=106.5^{\circ}$

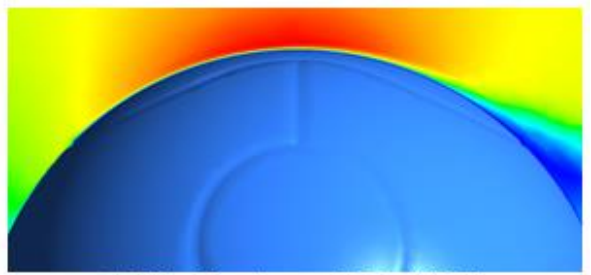

(c) $\mathrm{V}=30 \mathrm{~m} / \mathrm{s}, \varphi=0^{\circ}, \theta=115.3^{\circ}$

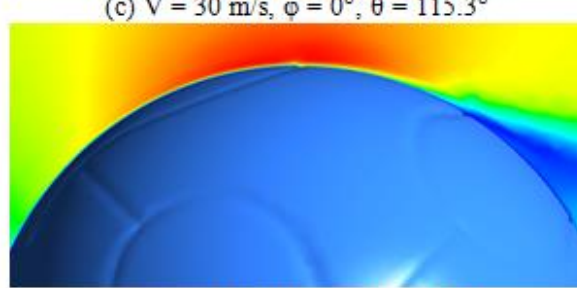

(f) $\mathrm{V}=30 \mathrm{~m} / \mathrm{s}, 0=45^{\circ}, \theta=112.9^{\circ}$

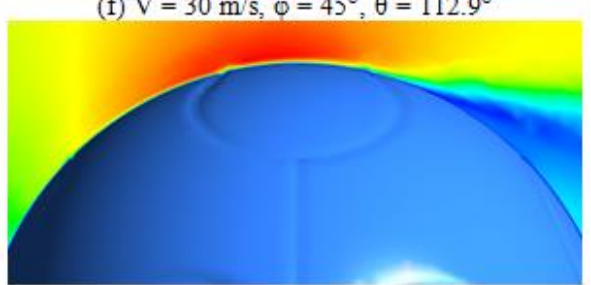

(i) $\mathrm{V}=30 \mathrm{~m} / \mathrm{s}, \mathrm{O}=90^{\circ}, \theta=104.6^{\circ}$

Fig 27:- shows the velocity profiles of Teamgeist at different panel orientation to analyze the HBL Separation Angle 


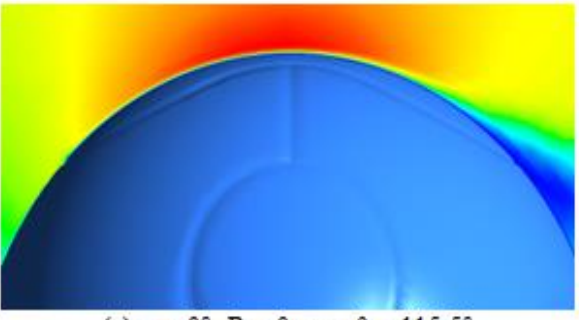

(a) $\varphi=0^{\circ}, \mathrm{R}=0 \mathrm{~mm}, \theta=115.5^{\circ}$

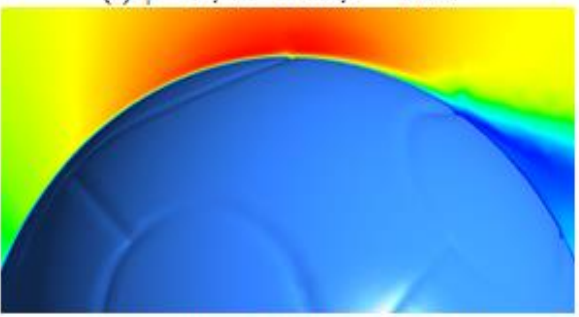

(d) $\varphi=45^{\circ}, \mathrm{R}=0 \mathrm{~mm}, \theta=114.9^{\circ}$

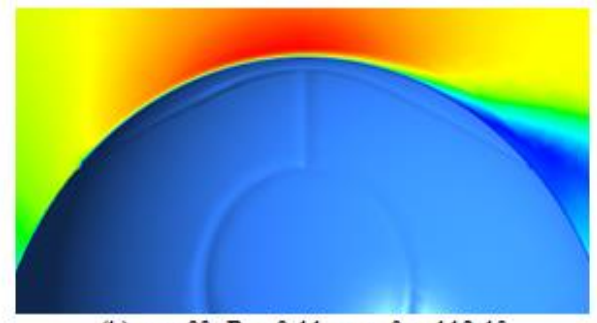

(b) $\varphi=0^{\circ}, \mathrm{R}=0.11 \mathrm{~mm}, \theta=112.1^{\circ}$

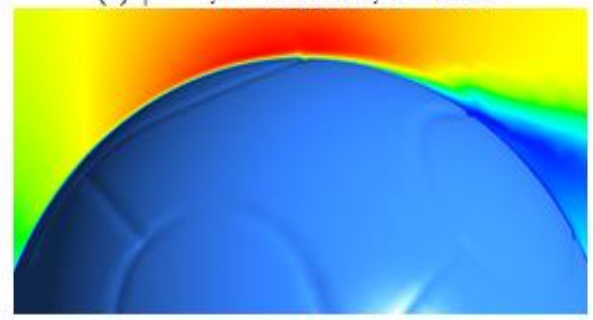

(e) $\varphi=45^{\circ}, R=0.11 \mathrm{~mm}, \theta=110.6^{\circ}$

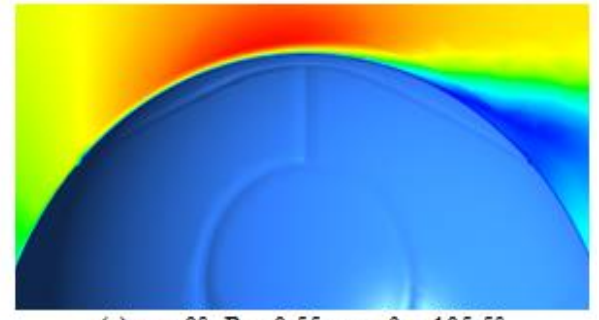

(c) $\varphi=0^{\circ}, \mathrm{R}=0.55 \mathrm{~mm}, \theta=105.5^{\circ}$

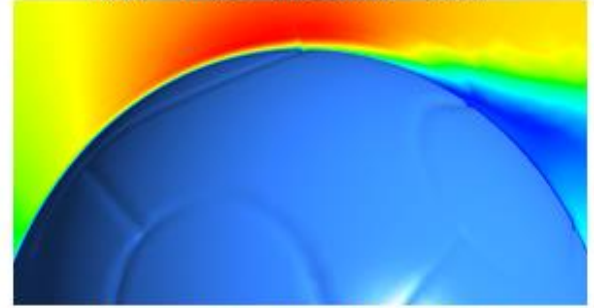

(f) $\varphi=45^{\circ}, R=0.55 \mathrm{~mm}, \theta=103.7^{\circ}$

Fig 28:- shows the velocity profiles of Teamgeist at $25 \mathrm{~m} / \mathrm{s}$ for different panel orientation with surface roughness to analyze the HBL Separation Angle

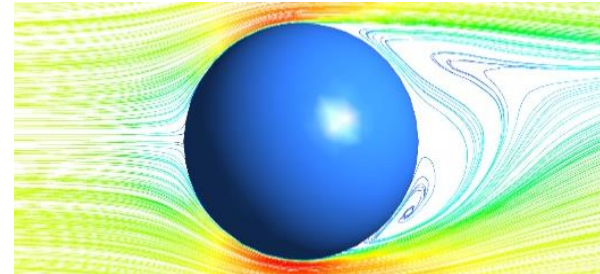

(a) $\mathrm{V}=10 \mathrm{~m} / \mathrm{s}, \mathrm{R}=0 \mathrm{~mm}, \mathrm{C}_{\mathrm{d}}=0.47$

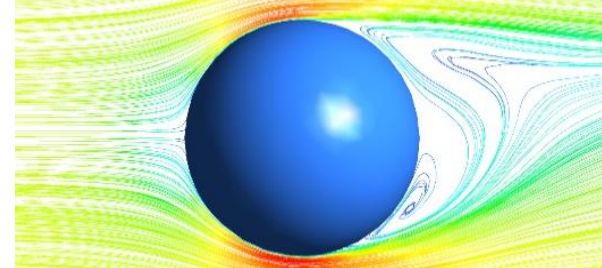

(d) $\mathrm{V}=10 \mathrm{~m} / \mathrm{s}, \mathrm{R}=0.11 \mathrm{~mm}, \mathrm{C}_{\mathrm{d}}=0.47$

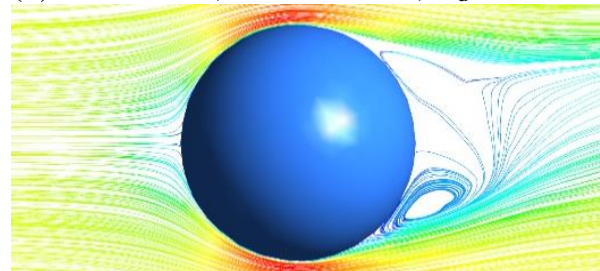

(g) $\mathrm{V}=10 \mathrm{~m} / \mathrm{s}, \mathrm{R}=0.55 \mathrm{~mm}, \mathrm{C}_{\mathrm{d}}=0.12$

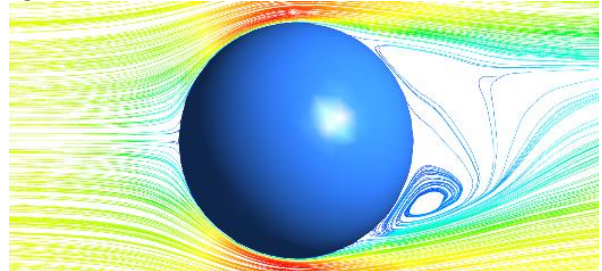

(j) $\mathrm{V}=10 \mathrm{~m} / \mathrm{s}, \mathrm{R}=2.75 \mathrm{~mm}, \mathrm{C}_{\mathrm{d}}=0.28$

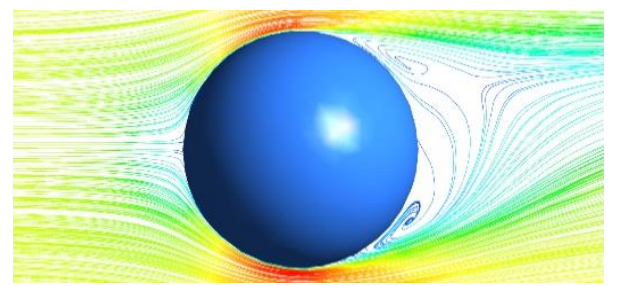

(b) $\mathrm{V}=20 \mathrm{~m} / \mathrm{s}, \mathrm{R}=0 \mathrm{~mm}, \mathrm{C}_{\mathrm{d}}=0.4$

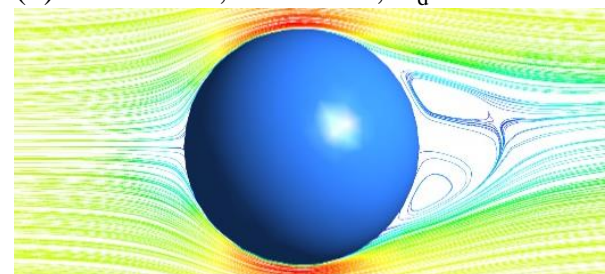

(e) $\mathrm{V}=20 \mathrm{~m} / \mathrm{s}, \mathrm{R}=0.11 \mathrm{~mm}, \mathrm{C}_{\mathrm{d}}=0.13$

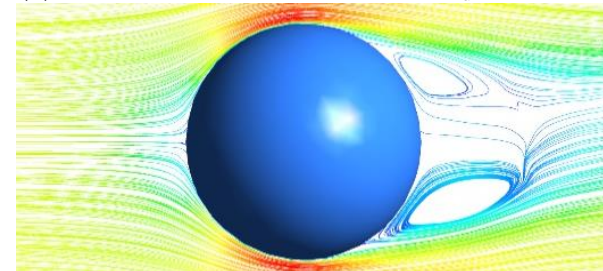

(h) $\mathrm{V}=20 \mathrm{~m} / \mathrm{s}, \mathrm{R}=0.55 \mathrm{~mm}, \mathrm{C}_{\mathrm{d}}=0.29$

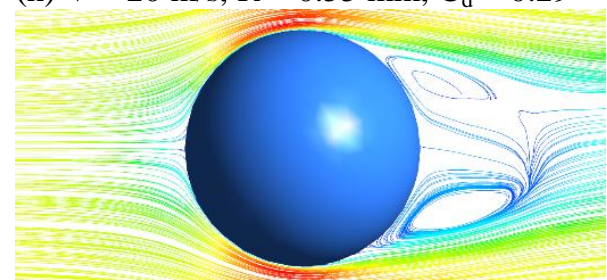

(k) $\mathrm{V}=20 \mathrm{~m} / \mathrm{s}, \mathrm{R}=2.75 \mathrm{~mm}, \mathrm{C}_{\mathrm{d}}=0.30$

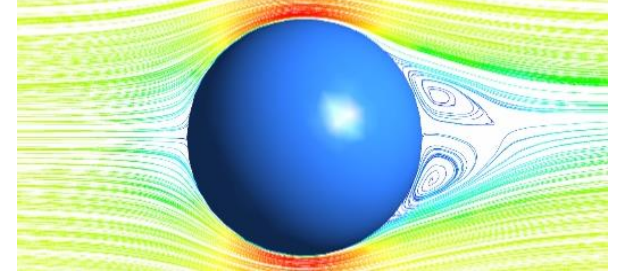

(c) $\mathrm{V}=30 \mathrm{~m} / \mathrm{s}, \mathrm{R}=0 \mathrm{~mm}, \mathrm{C}_{\mathrm{d}}=0.08$

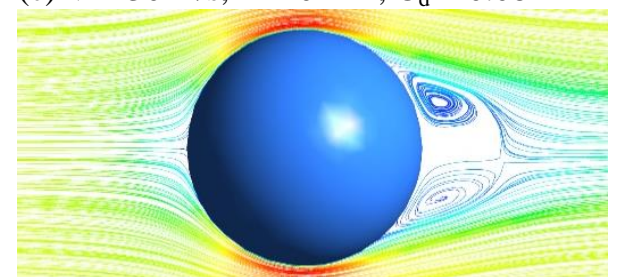

(f) $\mathrm{V}=30 \mathrm{~m} / \mathrm{s}, \mathrm{R}=0.11 \mathrm{~mm}, \mathrm{C}_{\mathrm{d}}=0.17$

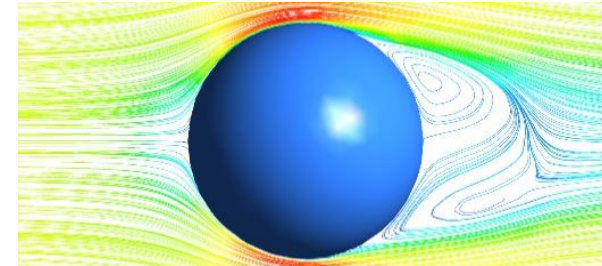

(i) $\mathrm{V}=30 \mathrm{~m} / \mathrm{s}, \mathrm{R}=0.55 \mathrm{~mm}, \mathrm{C}_{\mathrm{d}}=0.3$

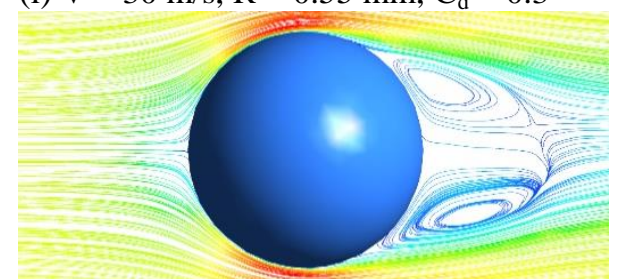

(l) $\mathrm{V}=30 \mathrm{~m} / \mathrm{s}, \mathrm{R}=2.75 \mathrm{~mm}, \mathrm{C}_{\mathrm{d}}=0.31$ Fig 29:- shows the Stream Lines of Sphere at different surface roughness to analyze the Wake region 


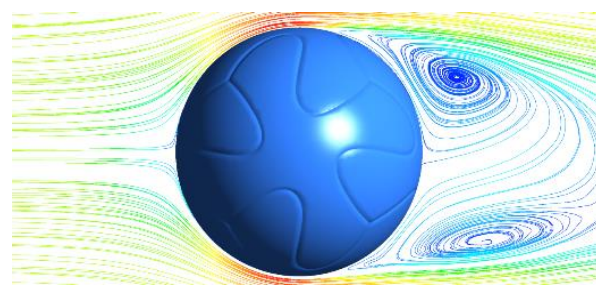

(a) $\mathrm{V}=10 \mathrm{~m} / \mathrm{s}, \mathrm{R}=0 \mathrm{~mm}, \mathrm{C}_{\mathrm{d}}=0.41$

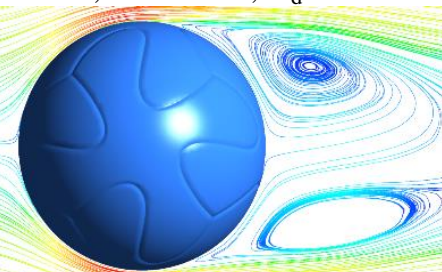

(d) $\mathrm{V}=10 \mathrm{~m} / \mathrm{s}, \mathrm{R}=0.11 \mathrm{~mm}, \mathrm{C}_{\mathrm{d}}=0.41$

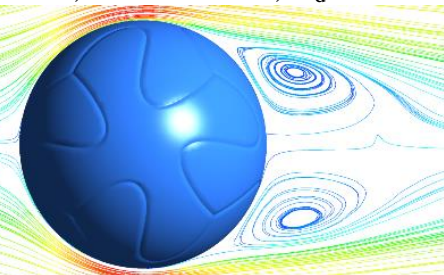

(g) $\mathrm{V}=10 \mathrm{~m} / \mathrm{s}, \mathrm{R}=0.55 \mathrm{~mm}, \mathrm{C}_{\mathrm{d}}=0.307$

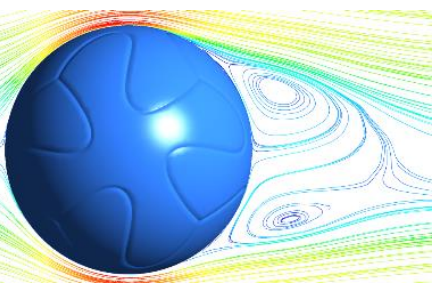

(b) $V=20 \mathrm{~m} / \mathrm{s}, \mathrm{R}=0 \mathrm{~mm}, \mathrm{C}_{\mathrm{d}}=0.19$

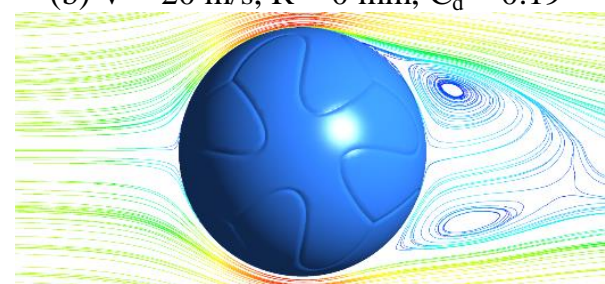

(e) $V=20 \mathrm{~m} / \mathrm{s}, \mathrm{R}=0.11 \mathrm{~mm}, \mathrm{C}_{\mathrm{d}}=0.22$

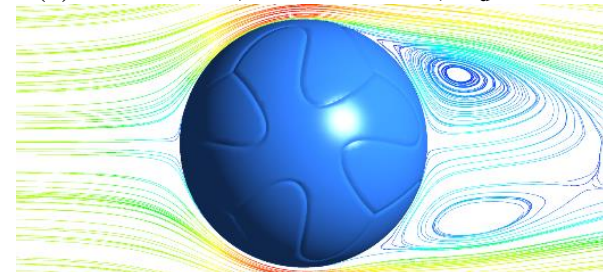

(h) $\mathrm{V}=20 \mathrm{~m} / \mathrm{s}, \mathrm{R}=0.55 \mathrm{~mm}, \mathrm{C}_{\mathrm{d}}=0.303$

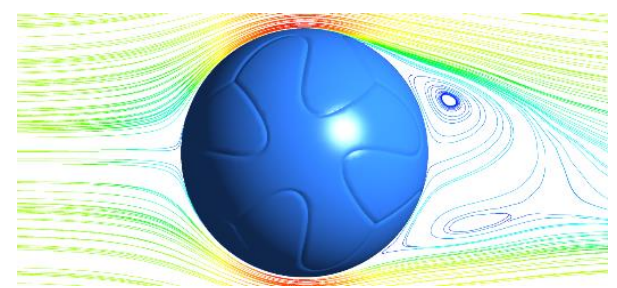

(c) $\mathrm{V}=30 \mathrm{~m} / \mathrm{s}, \mathrm{R}=0 \mathrm{~mm}, \mathrm{C}_{\mathrm{d}}=0.20$

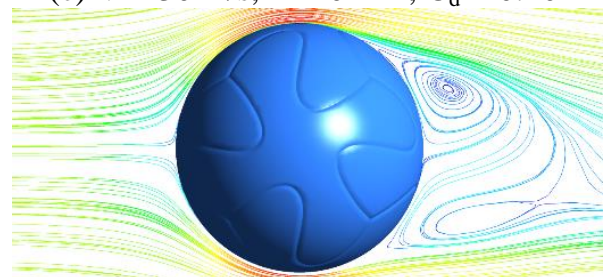

(f) $\mathrm{V}=30 \mathrm{~m} / \mathrm{s}, \mathrm{R}=0.11 \mathrm{~mm}, \mathrm{C}_{\mathrm{d}}=0.23$

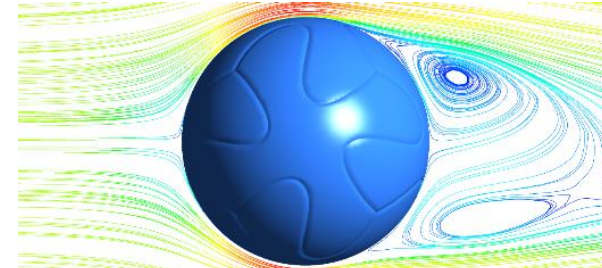

(i) $\mathrm{V}=30 \mathrm{~m} / \mathrm{s}, \mathrm{R}=0.55 \mathrm{~mm}, \mathrm{C}_{\mathrm{d}}=0.309$ Fig 30:- shows the Stream Lines of Brazuca at different surface roughness to analyze the Wake region

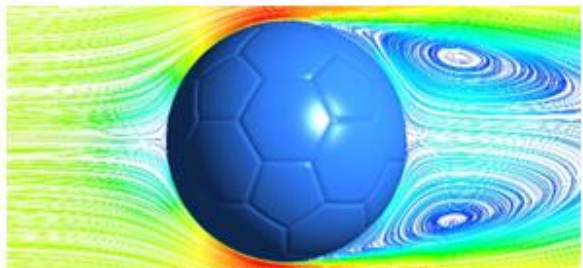

(a) $\mathrm{V}=10 \mathrm{~m} / \mathrm{s}, \mathrm{C}_{\mathrm{d}}=0.45$

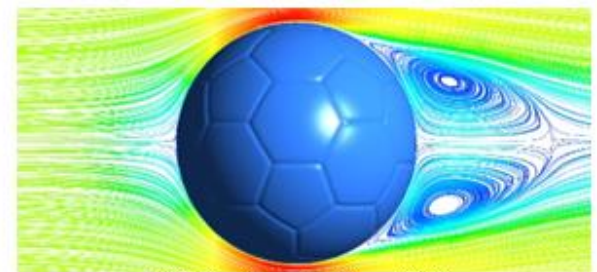

(b) $\mathrm{V}=20 \mathrm{~m} / \mathrm{s}, \mathrm{C}_{\mathrm{d}}=0.194$

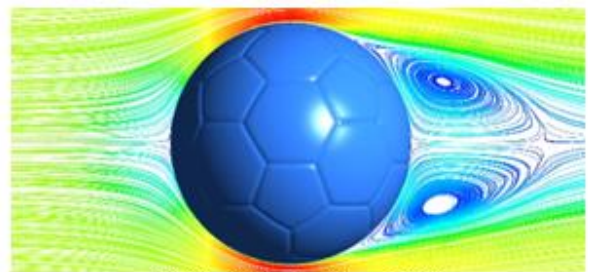

(c) $\mathrm{V}=30 \mathrm{~m} / \mathrm{s}, \mathrm{C}_{\mathrm{d}}=0.198$

Fig 31:- shows the Stream Lines of Conventional 32-Panel Ball to analyze the Wake region

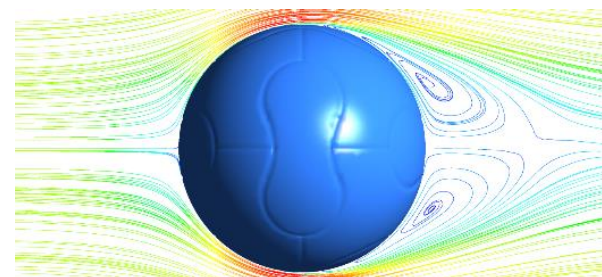

(a) $\mathrm{V}=10 \mathrm{~m} / \mathrm{s}, \varphi=0^{\circ}, \mathrm{C}_{\mathrm{d}}=0.433$

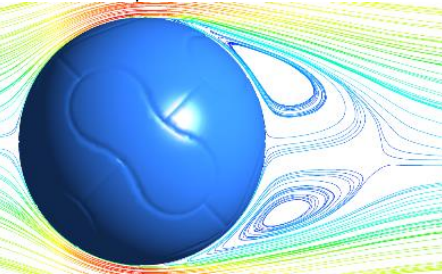

(d) $V=10 \mathrm{~m} / \mathrm{s}, \varphi=45^{\circ}, \mathrm{C}_{\mathrm{d}}=0.421$

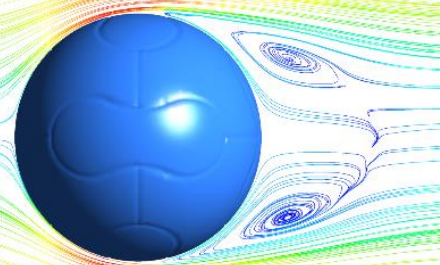

(g) $\mathrm{V}=10 \mathrm{~m} / \mathrm{s}, \varphi=90^{\circ}, \mathrm{C}_{\mathrm{d}}=0.435$

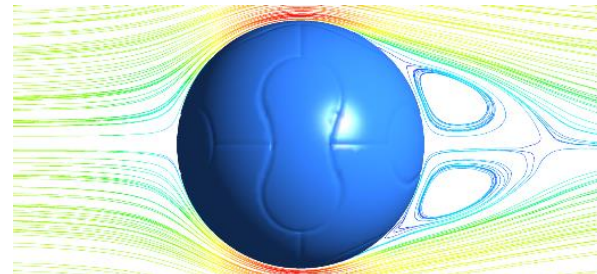

(b) $V=20 \mathrm{~m} / \mathrm{s}, \varphi=0^{\circ}, \mathrm{C}_{\mathrm{d}}=0.204$

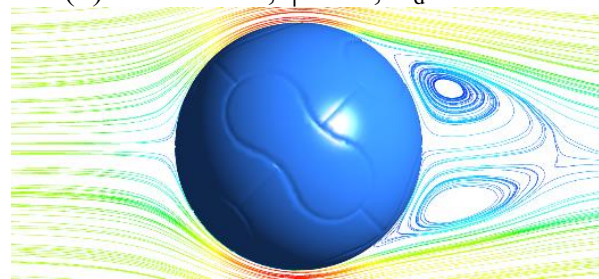

(e) $V=20 \mathrm{~m} / \mathrm{s}, \varphi=45^{\circ}, \mathrm{C}_{\mathrm{d}}=0.189$

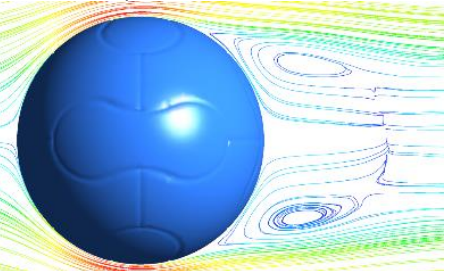

(h) $\mathrm{V}=20 \mathrm{~m} / \mathrm{s}, \varphi=90^{\circ}, \mathrm{C}_{\mathrm{d}}=0.207$

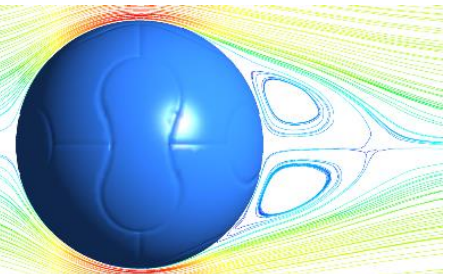

(c) $\mathrm{V}=30 \mathrm{~m} / \mathrm{s}, \varphi=0^{\circ}, \mathrm{C}_{\mathrm{d}}=0.205$

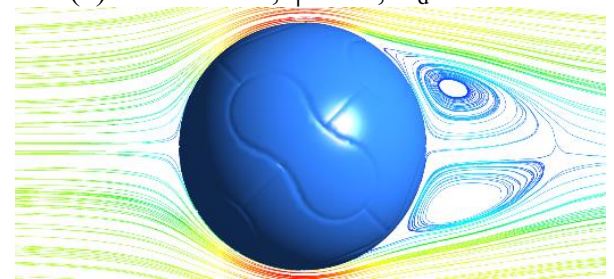

(f) $V=30 \mathrm{~m} / \mathrm{s}, \varphi=45^{\circ}, C_{d}=0.185$

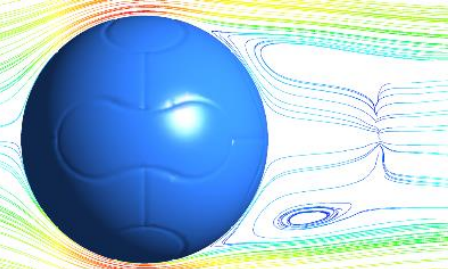

(i) $\mathrm{V}=30 \mathrm{~m} / \mathrm{s}, \varphi=90^{\circ}, \mathrm{C}_{\mathrm{d}}=0.209$

Fig 32:- shows the Stream Lines of Teamgeist at different panel orientation to analyze the Wake region 


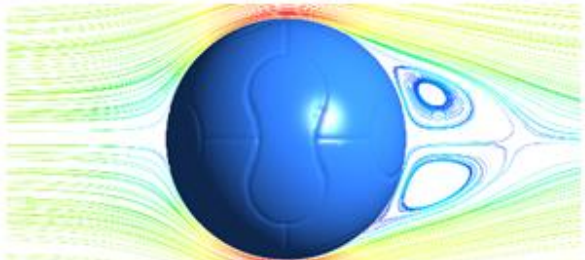

(a) $\varphi=0^{\circ}, \mathrm{R}=0 \mathrm{~mm}, \mathrm{C}_{\mathrm{d}}=0.204$

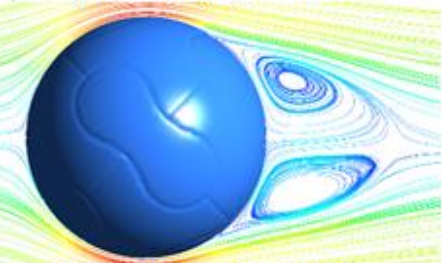

(d) $\varphi=45^{\circ}, \mathrm{R}=0 \mathrm{~mm}, \mathrm{C}_{\mathrm{d}}=0.187$

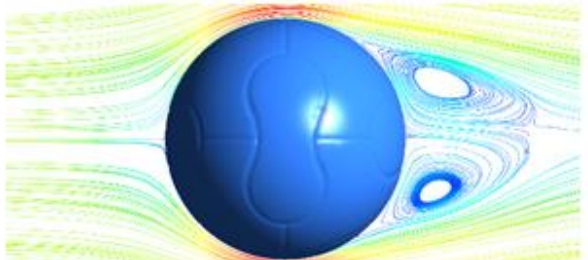

(b) $\varphi=0^{\circ}, \mathrm{R}=0.11 \mathrm{~mm}, \mathrm{C}_{\mathrm{d}}=0.227$

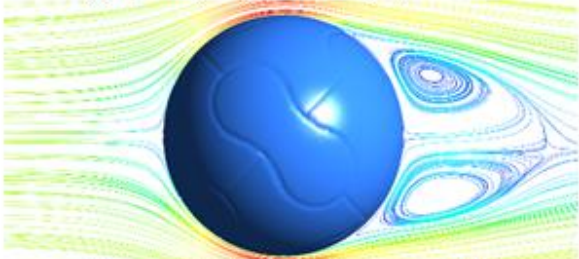

(e) $\varphi=45^{\circ}, \mathrm{R}=0.11 \mathrm{~mm}, \mathrm{C}_{\mathrm{d}}=0.22$

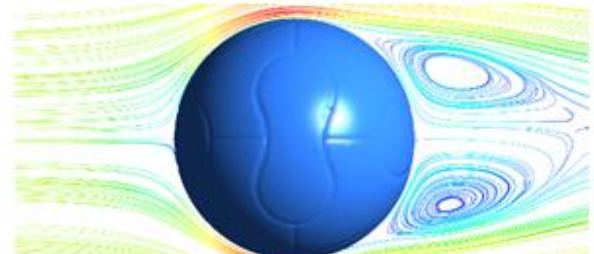

(c) $\varphi=0^{\circ}, \mathrm{R}=0.55 \mathrm{~mm}, \mathrm{C}_{\mathrm{d}}=0.299$

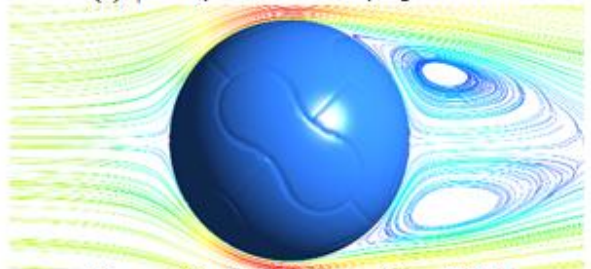

(f) $\varphi=45^{\circ}, \mathrm{R}=0.55 \mathrm{~mm}, \mathrm{C}_{\mathrm{d}}=0.298$

Fig 33:- shows the Stream Lines of Teamgeist at $25 \mathrm{~m} / \mathrm{s}$ for different panel orientation with surface roughness to analyze the Wake region 